\title{
Non-nebular origin of dark mantles around chondrules and inclusions in $\mathrm{CM}$ chondrites
}

\author{
Josep M. Trigo-Rodriguez ${ }^{\text {a,1 }}$, Alan E. Rubin ${ }^{\text {a }}$, John T. Wasson ${ }^{\text {a,b,c,* }}$ \\ a Institute of Geophysics and Planetary Physics, University of California, Los Angeles, CA 90095-1567, USA \\ ${ }^{\mathrm{b}}$ Department of Earth and Space Sciences, University of California, Los Angeles, CA 90095-1567, USA \\ c Department of Chemistry and Biochemistry, University of California, Los Angeles, CA 90095-1567, USA
}

Received 1 June 2005; accepted in revised form 7 November 2005

\begin{abstract}
Our examination of nine CM chondrites that span the aqueous alteration sequence leads us to conclude that compact dark fine mantles surrounding chondrules and inclusions in CM chondrites are not discrete fine-grained rims acquired in the solar nebula as modeled by Metzler et al. [Accretionary dust mantles in CM chondrites: evidence for solar nebula processes. Geochim. Cosmochim. Acta 56, 1992, 2873-2897]. Nebular processes that lead to agglomeration produce materials with porosities far higher than those in the dark mantles. We infer that the mantles were produced from porous nebular materials on the CM parent asteroid by impact-compaction (a process that produces the lowest porosity adjacent to chondrules and inclusions). Compaction was followed by aqueous alteration that formed tochilinite, serpentine, Ni-bearing sulfide, and other secondary products in voids in the interchondrule regions. Metzler et al. reported a correlation between mantle thickness and the radius of the enclosed object. In Yamato 791198 we find no correlation when all sizes of central objects and dark lumps are included but a significant correlation $\left(r^{2}=0.44\right)$ if we limit consideration to central objects with radii $>35 \mu \mathrm{m}$; a moderate correlation is also found in QUE 97990. We suggest that impact-induced shear of a plum-pudding-like precursor produced the observed "mantles"; these were shielded from comminution during impact events by the adjacent stronger chondrules and inclusions. Some mantles in CM chondrites with low degrees of alteration show distinct layers that may largely reflect differences in porosity. Typically, a gray, uniform inner layer is surrounded by an outer layer consisting of darker silicates with BSE-bright speckles. The CM-chondrite objects characterized as "primary accretionary rocks" by Metzler et al. did not form in the nebula, but rather on the parent body. The absence of solar-flare particle tracks and solar-wind-implanted rare gases in these clasts reflect their lithified nature and low surface/volume ratios during the period when they resided in the regolith and were subject to irradiation by solar particles. The clasts are analogous to the light-colored metamorphosed clasts in ordinary-chondrite regolith breccias (which also lack solar-flare particle tracks and solar-wind gas).
\end{abstract}

(c) 2005 Elsevier Inc. All rights reserved.

\section{Introduction}

Metzler et al. (1992) reported observations interpreted to show that chondrules and inclusions in CM carbonaceous chondrites are surrounded by compact, fine-grained

\footnotetext{
${ }^{*}$ Corresponding author. Fax: +1 3102063051.

E-mail address: jtwasson@ucla.edu (J.T. Wasson).

${ }^{1}$ Present addresses: Institut de Ciencies de l'Espai (CSIC), Campus UAB, Facultat de Ciencies, Torre C5-parell-2ona, 08193 Bellaterra (Barcelona), Spain; Institut d'Estudis Espacials de Catalunya (IEECCSIC) Edifici Nexus, c/Gran Capità, 2-4 80034 Barcelona, Spain.
}

dust mantles that formed in the solar nebula. In observations of large $(D>100 \mu \mathrm{m})$ cores, Metzler et al. (1992) stated that the mean thickness of these mantle shells is proportional to the size of the underlying (core) chondrule or inclusion (mantle thickness about $20 \%$ of core diameter). The interpretation is best summarized in the cartoon shown in their Fig. 6; Fig. 1 is a truncated version of this cartoon. Note the dense packing in Fig. 1c.

Back-scattered electron (BSE) images and electron-microprobe compositional totals show that these mantles have low $(10-20 \%)$ porosities, as low as, or lower than, the mean porosities of bulk CM chondrites. Broad-beam 


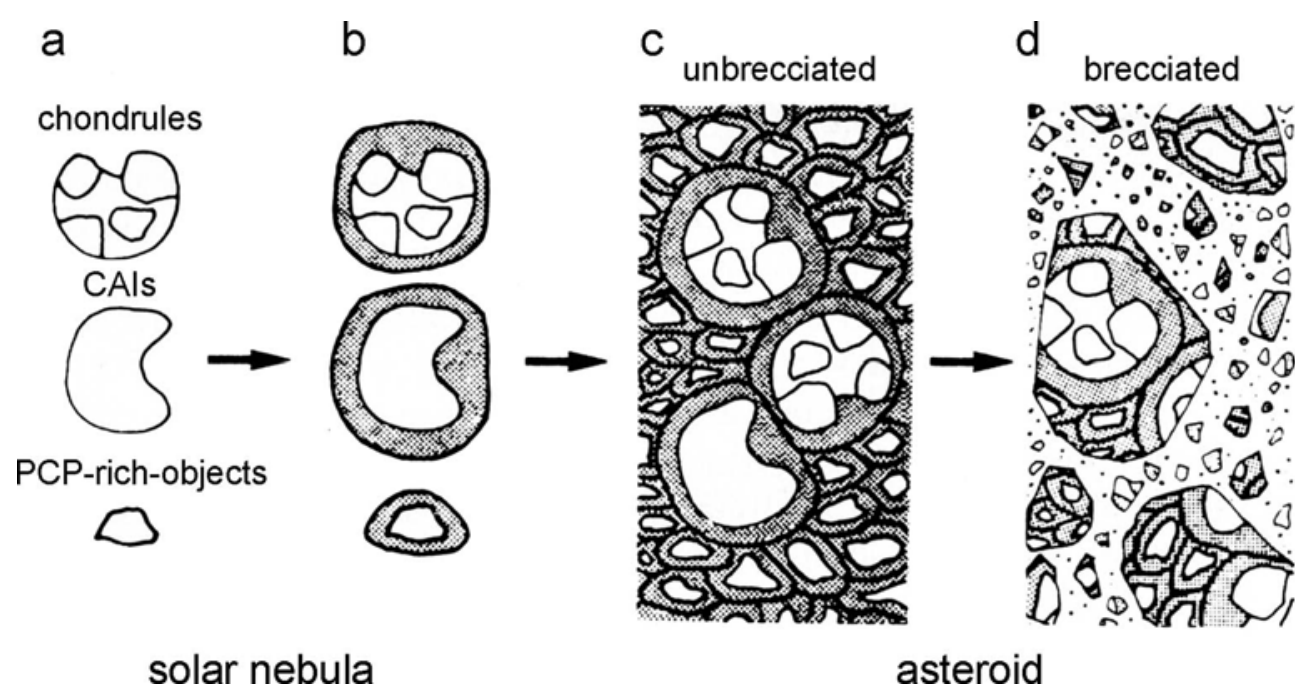

Fig. 1. Sketch showing a modified version of Fig. 6 of Metzler et al. (1992) illustrating their model for the formation of CM chondrites. (a) After having formed in the nebula, chondrules and CAIs exist as independent objects. (b) These objects acquire spheroidal mantles of fine-grained dust in the nebula. (c) The mantled objects accrete into "primary accretionary rocks" such as Y791198. (d) "Primary" rocks are brecciated on their parent body and form fragmental breccias such as Cold Bokkeveld.

electron-microprobe analyses of the mantles give totals that are low by $18-25 \%$, a measure of porosity and $\mathrm{H}_{2} \mathrm{O}$ content. As noted by Wasson (1995) and Wasson and Trigo-Rodríguez (2004), there seem to be no nebular processes that can produce such low porosities. This conclusion is supported by numerous studies, including that of Dominik and Tielens (1997) based on theoretical modeling, and those by Blum (2004); Blum and Schräpler (2004); and Blum and Wurm (2000) based on laboratory simulations.

$\mathrm{CM}$ chondrites are aqueously altered rocks that contain $\sim 10 \mathrm{wt} \% \mathrm{H}_{2} \mathrm{O}$ (Jarosewich, 1990) bound in phyllosilicate phases (mainly serpentines), tochilinite (an interstratified $\mathrm{Fe}-\mathrm{Ni}$ sulfide and $\mathrm{Fe}-\mathrm{Mg}$ hydroxide.

$2\left[(\mathrm{Fe}, \mathrm{Mg}, \mathrm{Cu}, \mathrm{Ni}[\mathrm{]}] \mathrm{S}] \cdot 1.57-1.85\left[(\mathrm{Mg}, \mathrm{Fe}, \mathrm{Ni}, \mathrm{Al}, \mathrm{Ca})(\mathrm{OH})_{2}\right]\right)$ (where the open bracket represents a vacancy), and, to a minor extent, hydrated $\mathrm{Mg}$ - and Ca-sulfates (Zolensky and McSween, 1988). Additional alteration products are pentlandite $\left[(\mathrm{Fe}, \mathrm{Ni})_{9} \mathrm{~S}_{8}\right]$ and Ni-bearing pyrrhotite $\left[\mathrm{Fe}_{1-x} \mathrm{~S}\right]$. The alteration phases are complex; in many $\mathrm{CM}$ chondrites they consist mainly of tochilinite and cronstedtite (an Fe-bearing serpentine; $\mathrm{Fe}_{2}{ }^{+2} \mathrm{Fe}^{+3}\left(\mathrm{SiFe}^{+3}\right)$ $\left.\mathrm{O}_{5}(\mathrm{OH})_{4}\right)$. Because these assemblages are Fe-rich, they appear bright in back-scattered electron (BSE) images. We will employ the time-honored term "poorly characterized phases" (PCP) for these BSE-bright, complex assemblages. Because the proportions of tochilinite and cronstedtite in PCP assemblages vary from spot to spot, unanalyzed individual PCP assemblages remain poorly characterized. The term PCP thus remains useful for petrographic descriptions of CM chondrites.

Also present in CM chondrites are grains of carbonate (mainly calcite and aragonite; Bunch and Chang, 1980; Barber, 1981), in some cases intergrown with tochilinite and serpentine (e.g., Fuchs et al., 1973), and grains of sul- fide (mainly pentlandite and pyrrhotite). Rare clusters of magnetite (Tomeoka and Buseck, 1985) and tiny grains of chlorite and gypsum (Lauretta et al., 2000) have also been reported. Brearley and Chizmadia (2005) described $\mathrm{Ca}$ phosphate at the interface between $\mathrm{FeO}$-rich chondrules and dark mantle material.

The members of the CM group can be arranged in a sequence of increasing whole-rock aqueous alteration (from moderately altered chondrites such as QUE 97990 to highly altered chondrites such as LAP 02277) on the basis of increased formation of phyllosilicates, oxidation of metallic $\mathrm{Fe}-\mathrm{Ni}$, destruction of isolated matrix silicate grains, alteration of mafic silicates within chondrules, increased PCP formation, changes in PCP composition, and the development of carbonate (e.g., Browning et al., 1996; Hanowski and Brearley, 2001; Rubin et al., 2005). Rubin et al. (2005) proposed a new scheme for assigning CM chondrites to an aqueous alteration sequence: hypothetically unaltered CM chondrites (perhaps similar to Acfer 094) are designated as petrologic type 3.0; highly altered rocks (presently classified as CM1 chondrites) such as LAP 02277 and MET 01070 that contain no mafic silicates but abundant chondrule pseudomorphs are designated type 2.0. The meteorites in the present study were classified as follows: QUE 97990, type 2.8; Murchison, type 2.7; Murray, type 2.6; Y791198, type 2.6; QUE 99355, type 2.4; Cold Bokkeveld, type 2.2; QUE 93005, type 2.1; LAP 02277, type 2.0; MET 01070, type 2.0.

Most workers have concluded that CM chondrites were aqueously altered on their parent asteroid rather than in the solar nebula (e.g., DuFresne and Anders, 1962; McSween, 1979, 1987; Kerridge and Bunch, 1979; Bunch and Chang, 1980; Richardson, 1981; Clayton and Mayeda, 1984; Tomeoka and Buseck, 1985; Browning et al., 1996; 
Hanowski and Brearley, 2001). Similar conclusions were reached for CO chondrites (e.g., Kerridge, 1972; Kojima et al., 1995; Rubin, 1998; Chizmadia et al., 2002) and CV chondrites (e.g., Krot et al., 1995, 1997; Tomeoka and Kojima, 1998; Tomeoka and Tanimura, 2000).

In addition to parent-body aqueous alteration, the CM chondrites have been affected by impact processes. For example, Murray is a regolith breccia (Price et al., 1975; Schultz and Kruse, 1989) containing highly altered magnetite- and sulfide-rich clasts, and numerous millimeter-size CM2 clasts that experienced different degrees of aqueous alteration (Bunch and Chang, 1980; Rubin and Wasson, 1986). Many other CM chondrites (e.g., Cold Bokkeveld, Haripura) are regolith or fragmental breccias (Schultz and Kruse, 1989) that contain $\sim 0.1-10$-mm-size angularto-subrounded CM clasts possessing well-defined chondrules. Cold Bokkeveld contains a clast that is itself a breccia (Metzler, 2004). Several CM chondrites (e.g., Murchison, Y74662) also exhibit foliations defined by preferentially oriented phyllosilicates (e.g., Fujimura et al., 1982). Sneyd et al. (1988) suggested that foliations in ordinary chondrites were caused by impact-induced deformation of the whole rocks; the same process is likely responsible for $\mathrm{CM}$ foliations.

In view of the low porosities $(\sim 10-20 \%)$ of the mantles that surround many chondrules, refractory inclusions, mineral fragments, pentlandite grains, carbonate grains, and even serpentine- and tochilinite-rich objects, and the extensive parent-body processing of CM chondrites, it seemed prudent to question the interpretation of $\mathrm{K}$. Metzler and colleagues (Metzler et al. (1992), Metzler and Bischoff (1996), Metzler (2004)) that the dark mantles are products of the solar nebula. Although a nebular origin for these mantles has been accepted by several research groups (e.g., Paque and Cuzzi, 1997; Cuzzi et al., 1998; Hua et al., 2002; Zega and Buseck, 2003; Cuzzi, 2004), there are no plausible mechanical (collisional) processes that produce porosities $<50 \%$ in a nebular setting (Dominik and Tielens, 1997; Blum and Wurm, 2000; Blum and Schräpler, 2004). We therefore reexamined the petrography of CM chondrites and especially the evidence cited by Metzler et al. (1992) with critical eyes.

\section{Analytical procedures}

We prepared mosaics of moderately high-resolution (2 $\mu \mathrm{m} /$ pixel) back-scattered electron (BSE) images of thin sections of nine CM chondrites that vary in their degree of aqueous alteration: Cold Bokkeveld (USNM 182-2); LAP (La Paz Ice Field) 02277,10; MET (Meteorite Hills) 01070,7; Murchison (USNM 5376-5); Murray (USNM 1769-7); QUE (Queen Alexandra Range) 93005,9; QUE 97990,13; QUE 99355,6; and Y(Yamato) 791198,90-1. The Murchison, Murray, and Cold Bokkeveld sections are from the Smithsonian Institution, the QUE, LAP, and MET sections are from NASA Johnson Space Center, and the Y791198 section is from the National Insti- tute of Polar Research in Japan. A millimeter grid was superimposed on each image; chondrules and other objects were assigned labels based on their locations within these grids. All BSE images were made with the LEO 1430 VP scanning electron microscope (SEM) at UCLA using a $15 \mathrm{keV}$ accelerating voltage and a working distance of $\sim 19 \mathrm{~mm}$. We also made 10-element X-ray maps of two different representative $1-\mathrm{mm}^{2}$ portions of six of the CM chondrites using the JEOL JXA-8200 electron microprobe at UCLA.

We estimated the areas of DFM mantles, central objects, and lumps by outlining these in Adobe Photoshop. For each region all objects in the investigated size range were included in the survey. More details are given in Section 3.3.4.

\section{Results and some interpretations}

A key goal in our studies is to understand and define the role of impacts both in compacting as well as shearing and brecciating the CM materials, and to assess how and when the final structures were affected by aqueous alteration.

The chief structural components of $\mathrm{CM}$ chondrites are chondrules, inclusions, DFM, and the Fe-rich alteration product PCP (and associated sulfide). These components are visible in BSE images from Y791198 (Figs. 2a and b). In both parts of Fig. 2 the four components are readily visible; the chondrules and inclusions have sharp borders, the DFM and PCP commonly have indistinct borders and, in some cases, are interfingering. As we discuss in detail below, the interrelationships between DFM and PCP are important for assessing the origin of "mantles"; during aqueous alteration, the PCP seems to have formed in cracks and other voids.

In Fig. 2a there are about a dozen dark (low-FeO) chondrules and chondrule fragments; most have no DFM mantles or nearby DFM distributions that are not obviously mantling. In most cases, the dark material around the chondrules grades into the surrounding matrix (i.e., center of image) or connects via narrow bridges to other DFM mantles. In Fig. $2 b$ the pyroxene-rich chondrule with the ellipsoidal S-rich inclusion on the right has a roughly symmetrical dark mantle. The chondrule at the left of Fig. $2 b$ has a thick DFM mantle that grades into matrix material directly above it. The boundaries between the mantle and surrounding matrix material are indistinct, particularly at high resolution. These two images are orthogonal; Fig. $2 \mathrm{a}$ is oriented according to our thin section grid; Fig. $2 b$ has been rotated $90^{\circ}$ to the right. This is important for the later discussion of shear effects.

In the remainder of this section we will first examine the key features of DFM and PCP, then provide a detailed assessment of the alteration sequence that uses several of these features. Section 3.3 is a lengthy discourse on mantles, DFM, and chondrules. The final subsection is a brief discussion of lineations. 


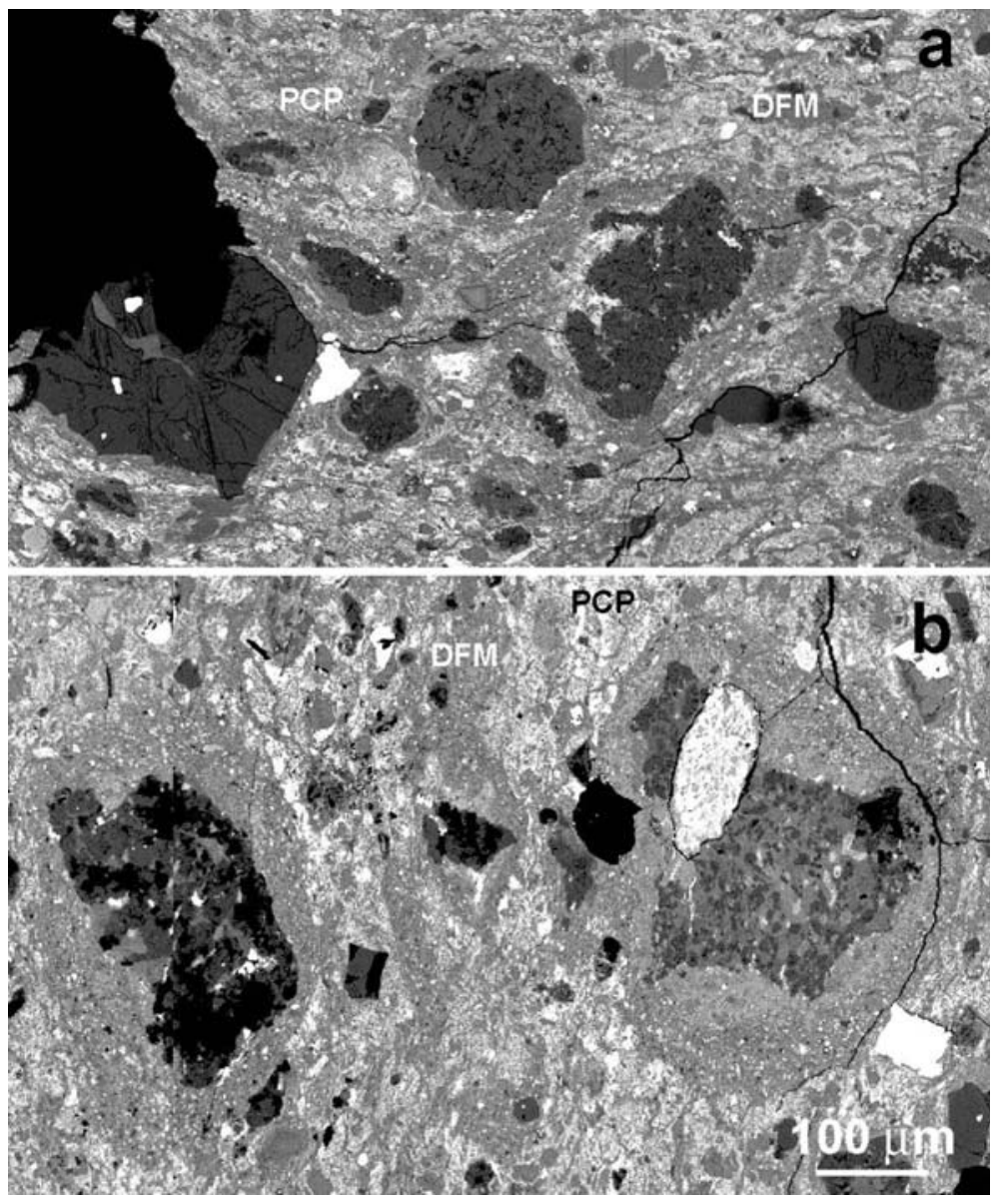

Fig. 2. Back-scattered electron (BSE) images of the major components present in Y791198. (a) About seven low-FeO chondrules and chondrule fragments (dark gray) occur amidst dark, fine-grained materials (DFM) (intermediate gray), poorly characterized phases (PCP) (light gray) and a few grains of iron sulfide (white); although some of these objects are adjacent to DFM, most do not have mantles. (The black patch at the left is part of the glass slide.) The PCP forms an apparent E-W lineation. (b) A pyroxene-rich chondrule (right) with a sulfide-rich ellipsoidal inclusion (white) is surrounded by a quasiequant dark mantle. Low- $\mathrm{FeO}$ chondrule at left is surrounded by a mantle that grades into adjacent matrix material. This image is orthogonal to the one in (a); consequently, the apparent PCP lineation in this image is $\mathrm{N}-\mathrm{S}$.

\subsection{BSE and EMP studies of mantle DFM (and variations)}

A key to using BSE images to help constrain the formation and evolution of the $\mathrm{CM}$ chondrites is to characterize the variations in size and abundance of the bright phase(s) that are common in the interchondrule regions. The brightness mainly reflects a high abundance of Fe. Fig. 3 shows images of one region of Murchison in BSE and in X-rays of $\mathrm{Fe}, \mathrm{S}, \mathrm{Si}, \mathrm{Mg}$, and $\mathrm{Na}$. The large $(D \sim 150 \mu \mathrm{m})$ chondrule fragment on the lower right has a uniform compact rim that is essentially free of PCP. In this region PCP is fine $(<5 \mu \mathrm{m})$; the presence of PCP can be recognized in the $\mathrm{BSE}, \mathrm{Fe}$ and, $\mathrm{S}$ images in small patches just beyond the chondrule mantle. In contrast, the $\mathrm{Si}, \mathrm{Mg}$, and $\mathrm{Na} \mathrm{X}$-ray images show an uniformity between the mantles and the patches with higher PCP because the $\mathrm{SiO}_{2}, \mathrm{MgO}$, and $\mathrm{Na}_{2} \mathrm{O}$ contents are similar in these lithologies.

In most cases, we have not analyzed the assemblages that appear bright in the BSE and Fe X-ray images, and therefore designate them simply by the generic term PCP. Because the modifier "mantling" includes an interpreta- tion, we will generally call the mantles and other materials having similar textures "dark, fine materials" or "DFM" and restrict mantles to roughly symmetric rimming structures around chondrules, chondrule fragments, and inclusions. Even within a single chondrite (e.g., Y791198), these DFM regions are not homogeneous (e.g., Figs. 2 and 4); some are brighter in BSE images (indicating a greater concentration of $\mathrm{Fe}$ ) and have a relatively uniform texture (e.g., stars in Figs. 4a and c); others are darker and have an overall texture that is more heterogeneous with light speckles in the darker host ("plus" symbols in Figs. 4a and c). Typically, the lighter gray areas are adjacent to the chondrule and the darker, speckled areas are outside them. Compositional characteristics of these layers are discussed below.

\subsection{BSE and EMP studies of PCP}

Quantitative electron-microprobe analysis of PCP shows compositional variations among different $\mathrm{CM}$ chondrites, within individual CM chondrites, and even among 

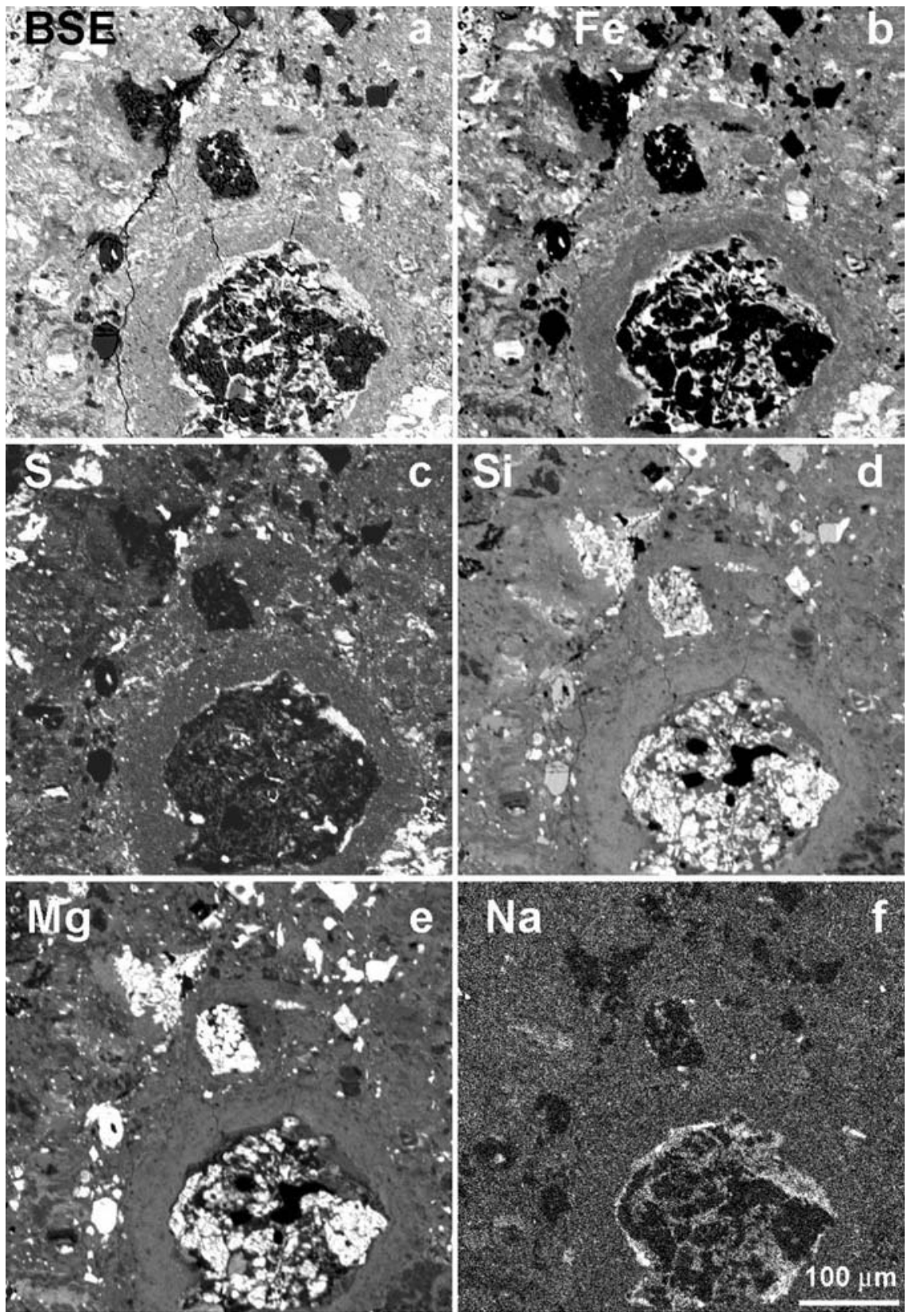

Fig. 3. A region of Murchison in (a) BSE and in X-rays of (b) Fe, (c) S, (d) Si, (e) Mg and (f) Na showing a low-FeO chondrule with altered mesostasis and phenocrysts surrounded by a fairly symmetric DFM mantle. Normal CM host material containing chondrule fragments, PCP and DFM occur above and to the left of the chondrule. As can be inferred from the S image (c), PCP forms speckles in the DFM outside the chondrule mantle. However, because PCP has similar concentrations of $\mathrm{Si}$ and $\mathrm{Mg}$ as DFM, it is barely discernable in the $\mathrm{Si}$ and $\mathrm{Mg}$ images. Sodium is enriched in the altered mesostasis of the chondrule but below the detection limit outside the chondrule. All images are to the same scale.

adjacent grains and grain clusters. For example, in QUE 97990 adjacent PCP clumps that appear nearly identical in BSE images vary in their $\mathrm{S} / \mathrm{SiO}_{2}$ weight ratios from 0.02 to 3.4 ; those in $\mathrm{Y} 791198$ vary in $\mathrm{S} / \mathrm{SiO}_{2}$ from 0.05 to 1.0 , and those in Cold Bokkeveld vary from 0.03 to 2.6 (Rubin et al., 2005). These compositional variations presumably reflect significant point-to-point variations in the proportions of serpentine, tochilinite, and sulfides.

Rubin et al. (2005) reported that the more-altered CM chondrites contain PCP that is richer in $\mathrm{SiO}_{2}, \mathrm{TiO}_{2}$,
$\mathrm{Al}_{2} \mathrm{O}_{3}, \mathrm{Cr}_{2} \mathrm{O}_{3}, \mathrm{MnO}, \mathrm{CaO}$, and $\mathrm{Na}_{2} \mathrm{O}$, and poorer in $\mathrm{FeO}$ and $\mathrm{S}$. Because $\mathrm{Fe}$ occurs in both phyllosilicates and sulfide, this trend may reflect an increase in the phyllosilicate/sulfide ratio of PCP during alteration. It may also reflect in part an increase in the $\mathrm{Mg}$ content of phyllosilicates during aqueous alteration as noted by Lauretta et al. (2000). Because LAP 02277 PCP has the lowest standard deviations for many of these elements, it seems likely that, with increasing aqueous alteration, PCP becomes more uniform in composition (Fig. 5). 


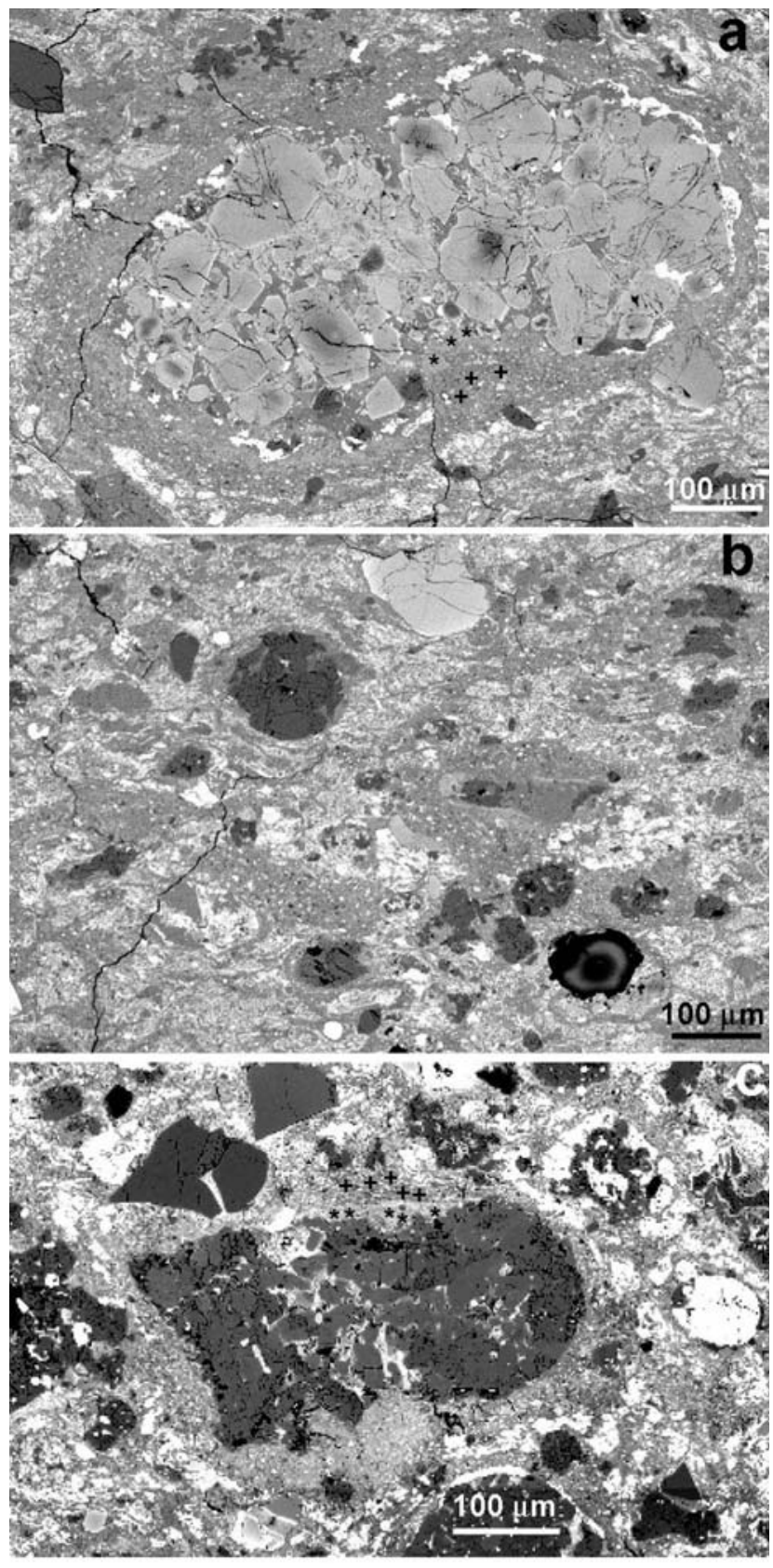

Fig. 4. BSE images of inhomogeneous mantles. (a) High-FeO chondrule in Y791198 with a layered mantle showing a discontinuous inner light layer with a relatively uniform texture (marked by stars) and an outer dark layer (marked by plus signs) that appears more heterogeneous and contains light speckles. (b) Asymmetric DFM mantles around small objects in Y791198 exhibiting heterogeneous layers. (c) Low-FeO chondrule in QUE 97990 surrounded by a heterogeneous mantle exhibiting a relatively uniform light layer (stars) and an outer dark layer with speckles (plus signs). The symbols mark points analyzed with the electron microprobe.

\subsection{Mantle, DFM, and chondrule interrelationships}

Metzler et al. (1992) characterized dark mantles as discrete, spheroidal-shaped structures consisting of finegrained, commonly serpentine- and tochilinite-rich, dust coatings that surround both high-temperature objects (i.e., chondrules, chondrule fragments, isolated mafic mineral grains, refractory inclusions, and amoeboid olivine inclusions) and low-temperature objects (e.g., cronstedtiteand tochilinite-rich assemblages, pentlandite, and calcite). According to Metzler et al., fine mantles range in thickness from $\sim 3$ to $\sim 400 \mu \mathrm{m}$, and are positively correlated with the radius of the enclosed object. Metzler et al. described mantles as being discrete structures, each rimming a single enclosed object. Support for this interpretation is provided in the form of low-magnification views of the mantled chondrules and grains (Figs. 1-5 of Metzler et al., 1992) and epitomized in their sketch shown above in Fig. 1.

\subsubsection{Y791198, a primary accretionary rock?}

Metzler et al. (1992) used the Y791198 structure as the touchstone for their interpretation. Fig. 6a shows the largest mantled object observed by Metzler et al. (1992). This object is in Y791198 and consists of a chondrule of radius $500 \mu \mathrm{m}$ and a mantle with a mean thickness of $400 \mu \mathrm{m}$. Even though the mantle is distinctive, it grades into the matrix at the bottom of the figure. Fig. $6 \mathrm{~b}$ shows details of the marked rectangle just to the left of the large chondrule. In this region the chondrules and inclusions are small, and the relationship between mantle thickness and size is unclear. We label several objects that are essentially unmantled.

Metzler et al. also noted that many mantles are layered: according to these workers, layers that appear brighter in BSE images are richer in PCP than darker layers. Their Fig. 15 shows a portion of a mantle with concentric layers (low $\mathrm{Fe}$-high $\mathrm{Fe}$-low $\mathrm{Fe}$ ) that vary somewhat in thickness. The bright intermediate layer is richer in Fe than the surrounding layers and appears similar to a thin partial Fe-rich layer immediately adjacent to the chondrule. Fig. 7 shows a very similar mantle structure around a low-FeO chondrule in our section of QUE 99355.

Metzler et al. (1992) singled out Y791198 as being a "primary accretionary rock," i.e., an unbrecciated, unaltered chondrite that developed its structure in the solar nebula and in which all components are surrounded by dark mantles. They reported that clasts of such "accretionary rock" materials are present in most CM chondrites (e.g., Fig. 7 of Metzler et al., 1992; see also Fig. 1 of Hanowski and Brearley, 2001).

\subsubsection{Discrete nature and symmetry of mantles}

Examination of our section of Y791198 shows DFM mantles around some but not all large chondrules; in particular, the smaller chondrules are less likely to have "mantles." Some DFM are present as irregular masses that enclose no sizable object. We also find that many chondrules and inclusions have no significant rims. Those DFM that are associated with chondrules and refractory inclusions typically have irregular shapes and frequently extend beyond the enclosed objects, grading into similar 

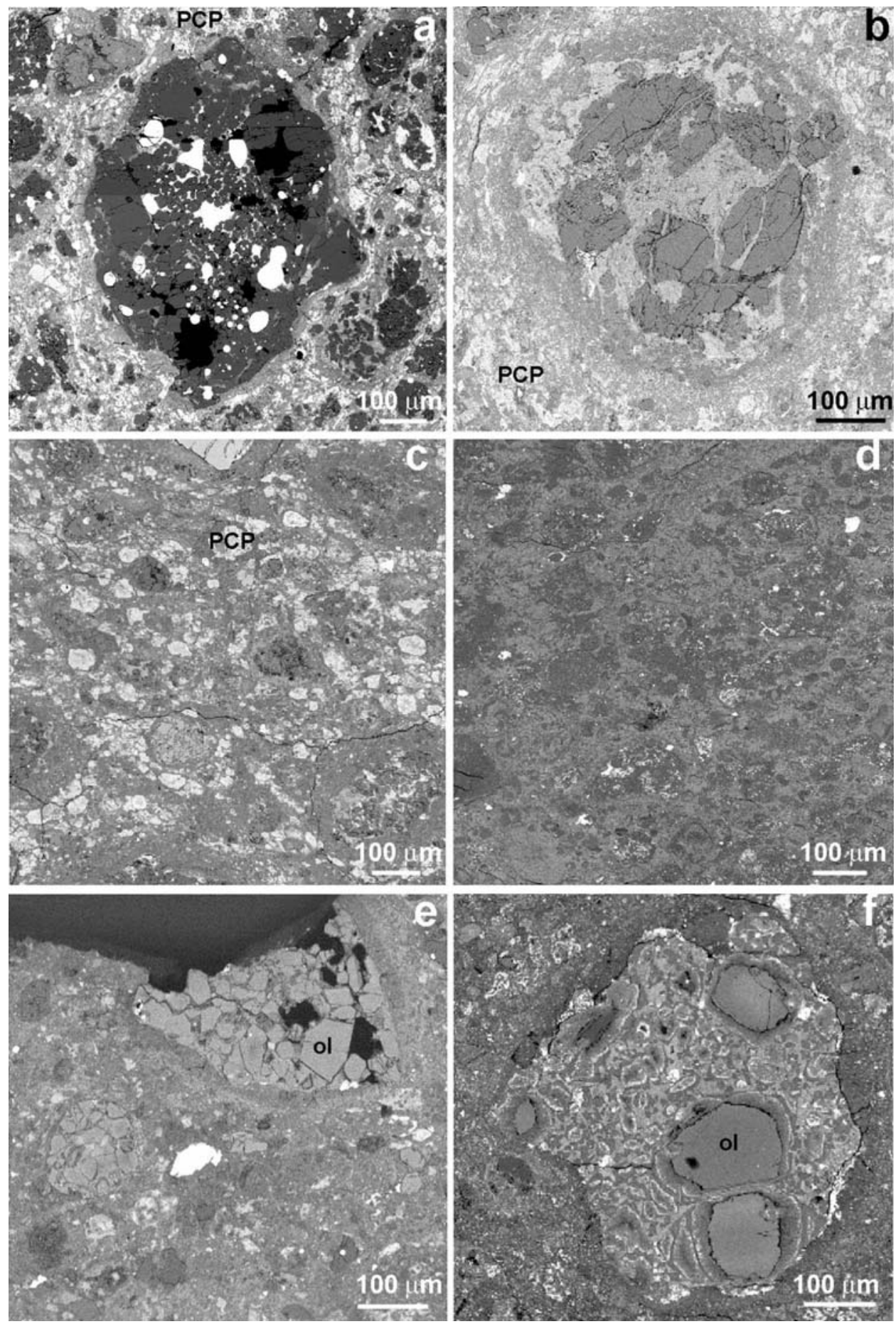

Fig. 5. BSE images documenting progressive textural changes in $\mathrm{CM}$ chondrites with increasing aqueous alteration. Metallic $\mathrm{Fe}-\mathrm{Ni}$ in low-FeO chondrules is moderately abundant in (a) QUE 97990 and absent in (b) Cold Bokkeveld. The abundance of coarse PCP clumps is high in (c) QUE 99355 and low in (d) LAP 02277. High-FeO olivine (ol) phenocrysts are intact and unaltered in (e) Murray and highly altered in (f) QUE 93005.

DFM in the surrounding meteorite matrix. In many cases, there are several chondrule or inclusion fragments enclosed within a single DFM mass.

In our thin section of Y791198, it is difficult to draw a boundary between some dark mantles and the surrounding matrix material (e.g., Fig. 8). For example, the refractory inclusion in Fig. 8a is surrounded by a dark mantle, but this mantle connects with DFM all around the inclusion, particularly near the top. The dark mantle around the chondrule fragment in Fig. 8c is connected via a bridge to a patch of DFM below it.

An illuminating example is a high- $\mathrm{FeO}$ porphyritic olivine chondrule fragment in Y791198 (Fig. 8d) that is surrounded by a dark mantle; this material grades into 


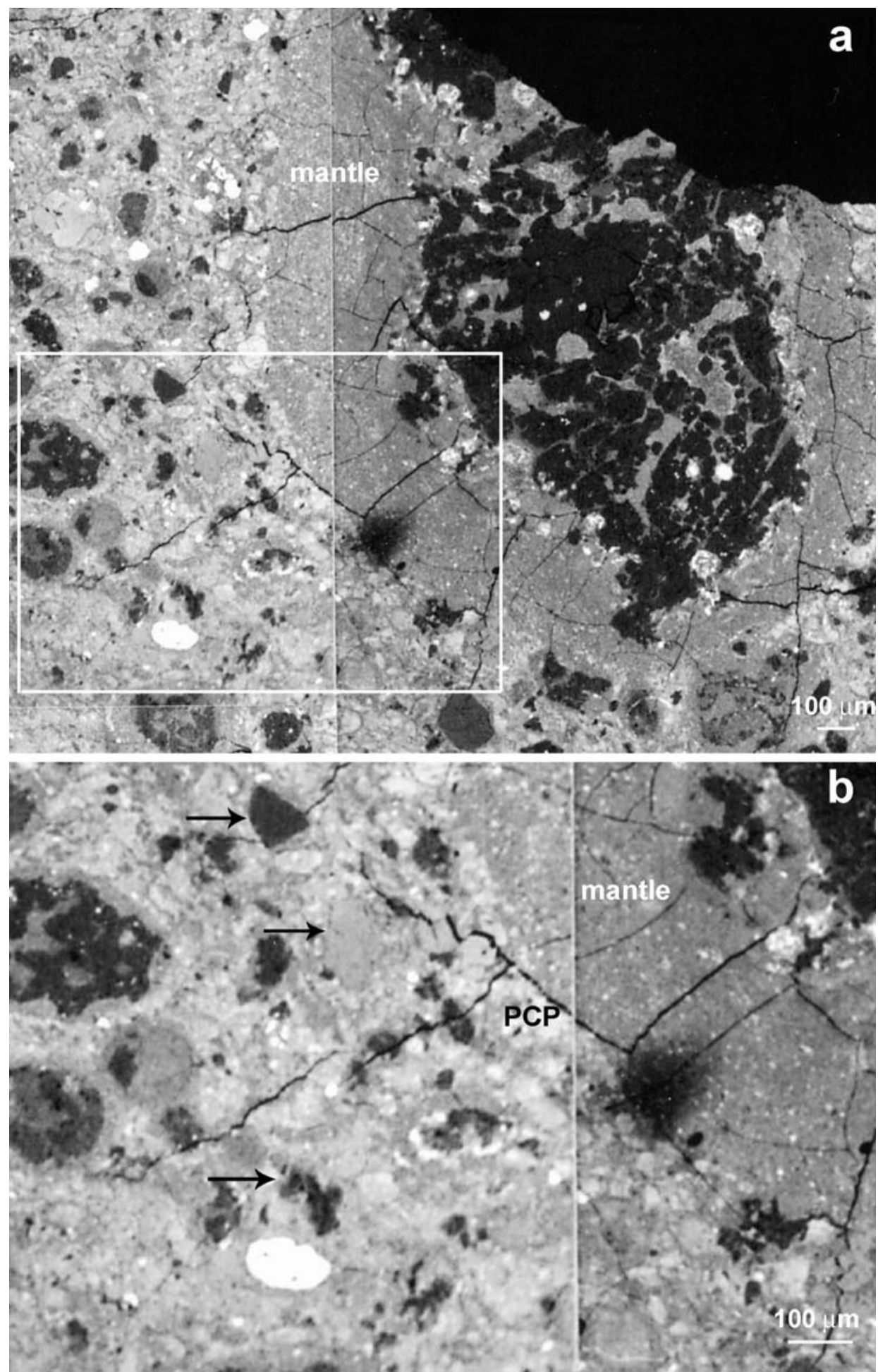

Fig. 6. BSE image of the largest mantled object observed by Metzler et al. (1992). (a) The ca. 1-mm-diameter low-FeO chondrule surrounded by a $\sim 400-$ $\mu \mathrm{m}$-thick mantle and adjacent PCP-bearing matrix. The rectangle marks the region shown in (b). (b) Higher magnification view of the rectangle in (a) showing small chondrule fragments and sulfide grains are not clearly mantled. Image courtesy of K. Metzler.

DFM regions below the chondrule fragment and into a seemingly discrete patch of DFM. The DFM adjacent to the chondrule does not appear to be a rim; any boundary lines drawn would be arbitrary.

\subsubsection{Dark fine materials in $C M$ chondrites}

Because QUE 97990 is among the least-altered CM chondrites, it offers the closest approximation to the DFM distribution prior to extensive aqueous alteration. 


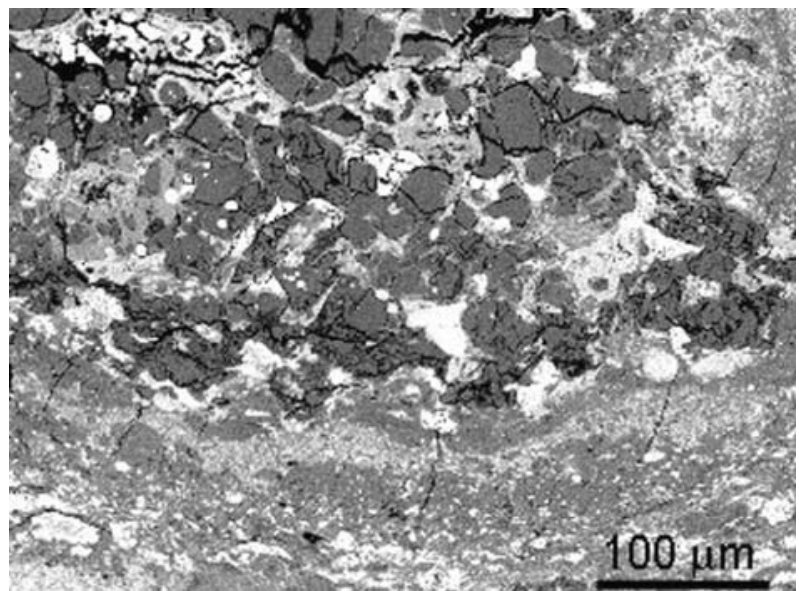

Fig. 7. Triple-layered mantle around a low-FeO chondrule in QUE 99355. The layers are of variable thickness. The intermediate layer (light gray) is richer in PCP than the adjacent layers and may have been formed by infilling of PCP in a fracture within a previously more homogeneous mantle. BSE image. Figure 15 of Metzler et al. (1992) shows a very similar structure in CM2 Kivesvaara.

A typical high-FeO porphyritic olivine chondrule (Fig. 9a) in this meteorite has a dark mantle that forms a textural continuum with DFM on all sides. It is impossible to draw a definite boundary between the mantle and surrounding matrix. Also present in this meteorite are disconnected low-FeO-porphyritic-olivine-chondrule fragments that are surrounded as an ensemble by DFM that interfingers with PCP (Fig. 9b). The DFM is only abundant on the right side of the largest fragment and between this fragment and smaller fragments at the 12 and 7 o'clock positions.

The indistinctiveness of DFM mantles is not restricted to QUE 97990. Every CM2 chondrite contains numerous chondrules with mantles that grade into surrounding matrix material. For example, two typical FeO-rich chondrules in Murchison (e.g., Figs. 10a and b) have mantles that merge into the surrounding DFM material in the matrix on all sides. In Fig. 10b, it is impossible to draw a definite boundary between the FeO-rich chondrule in the center and the low-FeO chondrule fragments at lower left. In QUE 99355 (Figs. 10c-f) dark mantles extend beyond the enclosed chondrules and into texturally similar interchondrule DFM material (e.g., bottom right center of Figs. 10c and d; top of Fig. 10e).

The occurrence of clasts of dark mantle material (Figs. $8 \mathrm{~b}$ and $\mathrm{e}$, and $11 \mathrm{a}$ and $\mathrm{b}$ ) is inconsistent with the simple picture that dark mantles are rims surrounding chondrules and inclusions. A spectacular example from QUE 99355 (Fig. 11a) consists of three disconnected, curved bands of layered dark mantle material that do not now enclose any coarse objects. The bands are $75-100 \mu \mathrm{m}$ thick and $250-550 \mu \mathrm{m}$ long, and are oriented in different directions. Their shapes, however, suggest that they could be fragments of a dark mantle dislodged from a core, possibly a chondrule (akin to the one in Fig. 7), during late-stage parent-body brecciation. If these bands are parts of a mantle formed in the nebula (which we deem very unlikely), then these were remarkably strong and compact nebular fines.

Although some dark mantles are roughly circular in section (e.g., Figs. 2b and 10c), most mantles are asymmetric (e.g., Figs. 2a, 8c and d, and 9b) and many are angular (e.g., Figs. 4b and 12a). Most isolated dark clasts (e.g., Figs. 8d and 11a) are also not spheroidal.

\subsubsection{Correlation between mantle thickness and diameter of enclosed object}

Metzler et al. (1992) reported significant correlations in several CM chondrites between the thickness of dark mantles and the apparent diameters of the enclosed objects; data plotted in their Fig. 17 show strong correlations in Kivesvaara, Y791198, Y74662, and Murray. They concluded that "...small chondrules are surrounded by thin dust layers, large chondrules by thick layers." Although the implication of this diagram is that chondrules of all sizes are included, in fact the correlations mainly result from observations on the largest $(\geqslant 60-\mu \mathrm{m}$ size) chondrules.

To aid understanding of the relationship between DFM and coarse materials we carried out detailed modal analyses of several square millimeters of two CM chondrites. We chose Y791198 (because Metzler et al. (1992) designated it a "primary accretionary rock") and QUE 97990 (because, among the CM chondrites that we studied, it shows the least amount of aqueous alteration). In Y791198, we also examined all chondrules or inclusions having radii $>35 \mu \mathrm{m}$.

We used Adobe Photoshop to estimate "mantle" thicknesses; we outlined the areas of the core objects (mainly chondrules or chondrule fragments) and of the total (core plus mantle) objects (Fig. 13). From these areas we calculated the mean radii of the core and of the total object; the difference between these values was defined to be the thickness of the mantle. Asymmetric mantles were assigned thicknesses in the same fashion. Mantles that enclose two or more cores were separated by a linear division drawn closer to the smaller object, the relative distances chosen to be roughly proportional to the respective core radii.

We conducted two surveys. In the first all core objects with mean radii $\geqslant 15 \mu \mathrm{m}$ were included, as were all DFM lumps with mean radii $\geqslant 15 \mu \mathrm{m}$ (Fig. 14). We measured some objects with smaller sizes, but because these are more difficult to resolve, our survey of these smaller objects may be incomplete. If the latter contains mafic grains with radii $\geqslant 4 \mu \mathrm{m}$, these were treated as "cores." If no grain this large was present, a core radius of $1 \mu \mathrm{m}$ was assumed for plotting purposes. Because of its labor-intensive nature, this survey was limited to $3 \mathrm{~mm}^{2}$ in the Y791198 section and $1 \mathrm{~mm}^{2}$ in the QUE97990 section. In the second study, we increased the minimum central-object radius to $35 \mu \mathrm{m}$ and surveyed every central object in our Y791198 section.

The results of our first survey are summarized in Table 1 and in Fig. 14. We note that the percentage of "mantled" chondrules is higher in Y791198 than in the less-altered 

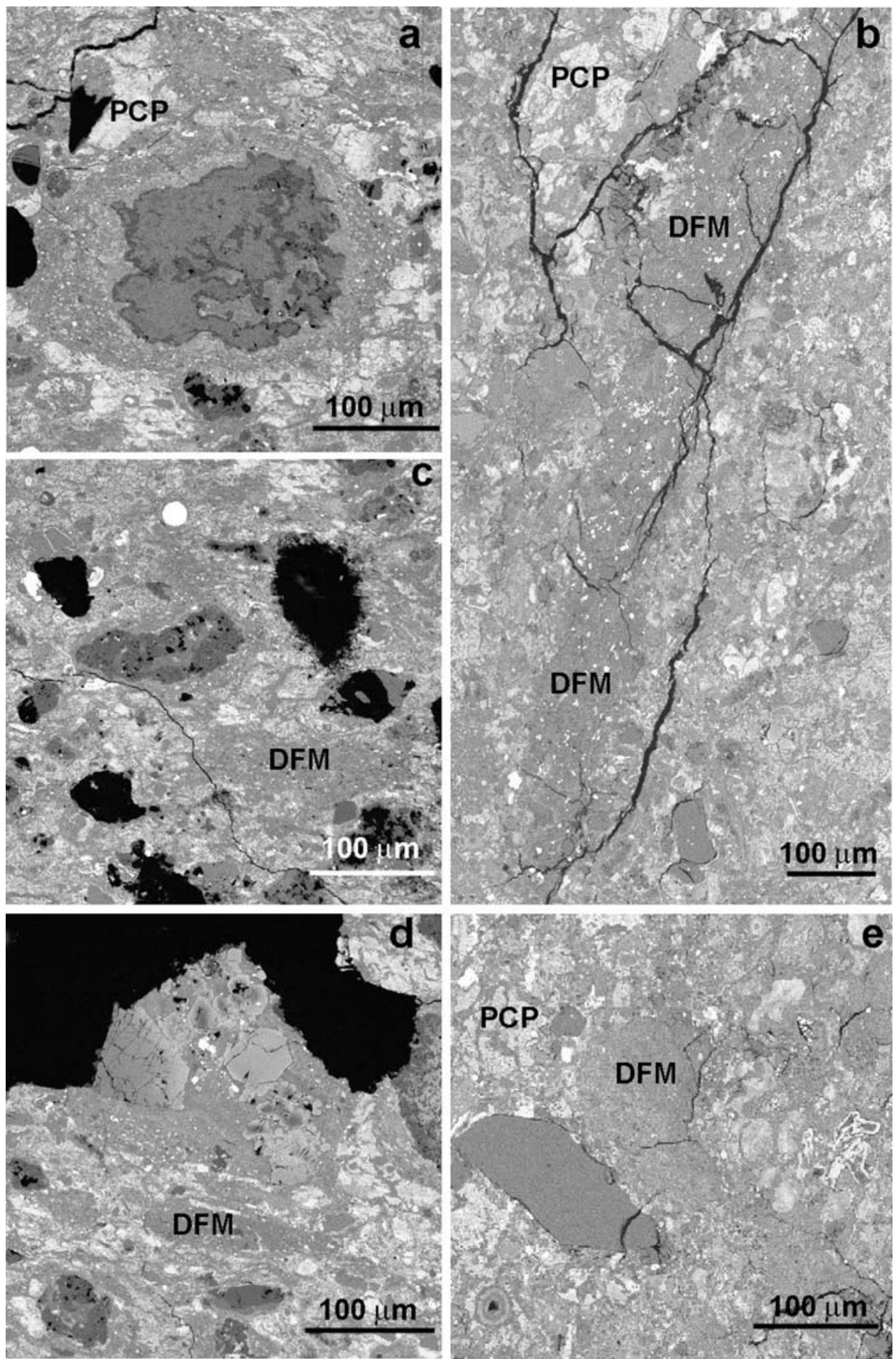

Fig. 8. BSE images of asymmetric mantles in Y791198. (a) CAI surrounded by a mantle that connects with surrounding DFM material. (b) Elongated patch of DFM in Cold Bokkeveld that contains a speckled texture consisting of small patches of PCP. (c) Elongated low-FeO chondrule fragment enclosed by a mantle that is connected by a bridge to a patch of DFM below it. (d) Fragmented, disconnected high-FeO chondrule embedded in an irregular patch of DFM that does not appear to be a mantle around the chondrule. (e) Isolated DFM patch adjacent to a high-FeO olivine grain in Cold Bokkeveld.

QUE 97990. For smaller sizes measured in the $3 \mathrm{~mm}^{2}$ survey of Y791198 a significant fraction of the objects is unmantled (Table 1). Fig. 14 presents plots of Y791198 and QUE 97990 showing unmantled objects and also abun- dant DFM lumps. From this figure we notice that the size of the objects studied in QUE 97990 is systematically smaller; $\sim 20 \mu \mathrm{m}$ in QUE $97990, \sim 35 \mu \mathrm{m}$ in Y791198. As can be seen from the correlation lines, the mean mantle thickness 


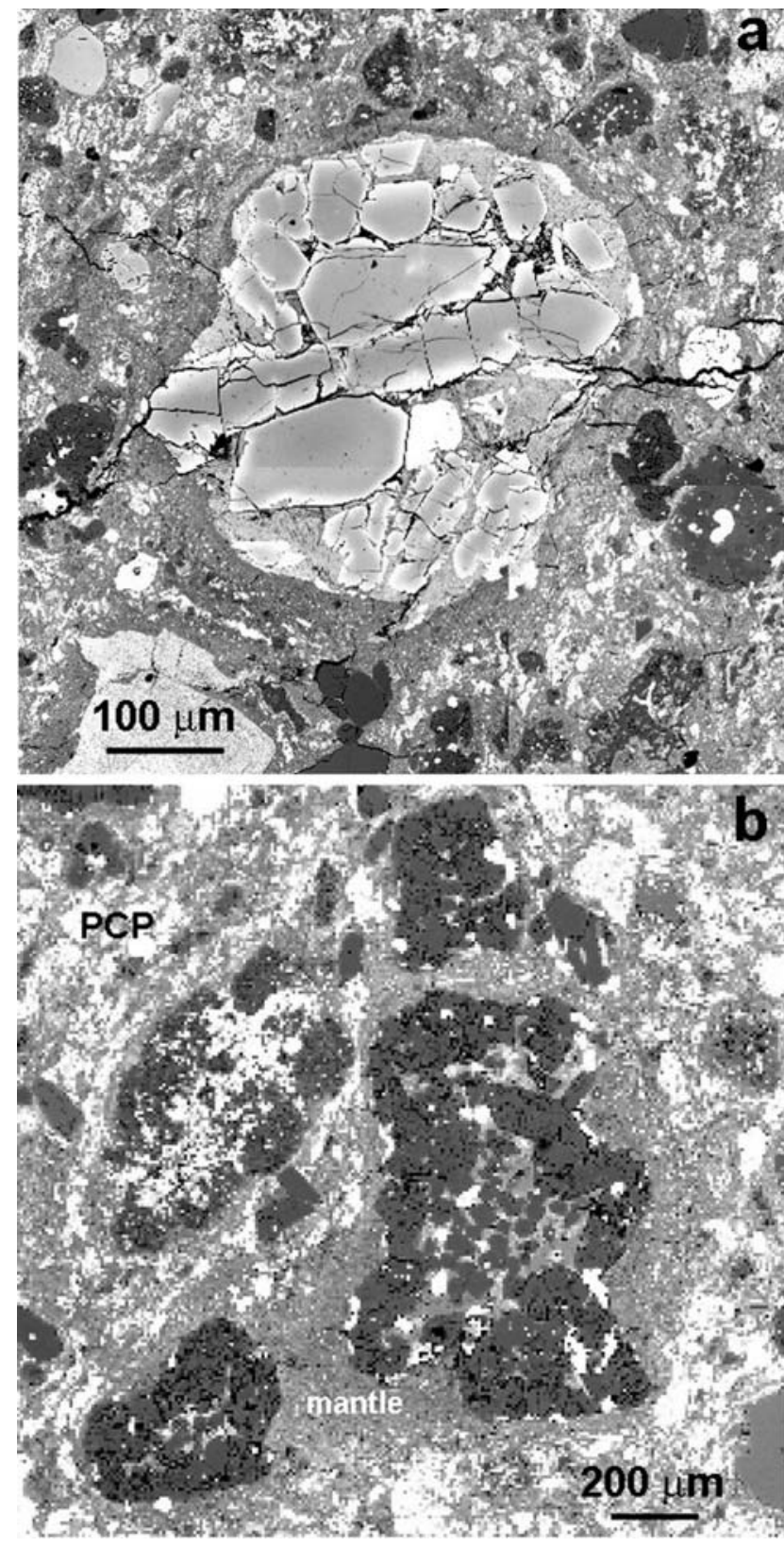

Fig. 9. Chondrules with irregular dark mantles in QUE 97990. (a) High$\mathrm{FeO}$ porphyritic olivine chondrule with a dark mantle that grades into surrounding dark matrix material on the left and right sides. (b) Separated low-FeO porphyritic chondrule fragments that are embedded in the same continuous dark mantle. Both images in BSE.

(roughly represented by the dashed lines) is $\sim 3.5 \times$ smaller in QUE 97990 than in Y791198 (Fig. 15).

We show two regression lines on each part of Fig. 14. The solid lines include the DFM lumps, the dashed lines do not include these. Unlike Metzler et al. (1992), we included all objects (cores without mantles and DFM lumps without sizable cores). This survey for large objects exhibits a positive correlation $\left(r^{2}=0.44\right)$ and a slope of 0.15 .

\subsubsection{Layering}

Some DFM mantles appear layered in BSE images. In some cases, the inner layer is darker than the outer layer (e.g., Fig. 13 of Metzler et al., 1992). In the least-altered $\mathrm{CM}$ chondrites, the common situation is that the inner layer is gray and relatively uniform in texture whereas the outer layer consists of dark silicates and bright PCP speckles (e.g., Figs. 4a and c). A few rare mantles have three or more resolvable layers of variable thickness and texture (e.g., Fig. 15 of Metzler et al., 1992; Fig. 7). In most cases it is misleading to refer to lighter and darker lithologies as layers; the textural variations occur as patches that have only moderate radial symmetry (e.g., Figs. 7, 8c, and 11b).

In general, bright layers are coarser grained and richer in PCP (Brearley and Geiger, 1991; Metzler et al., 1992). The light layers in "mantles" are generally more uniform and the grain size is generally smaller than in coarse bright regions in the interchondrule regions (e.g., Figs. 2 and 12).

Table 2 shows electron-microprobe data for inner layers that appear uniform in shade and outer layers with BSEbright speckles around chondrules in CM2.6 Y791198 (the "primary accretionary rock" of Metzler et al., 1992). Speckled layers differ from the inner layers in having lower $\mathrm{FeO}$ (25.8 vs. $32.3 \mathrm{wt} \%$ ), higher $\mathrm{SiO}_{2}$ (29.8 vs. 23.9 wt $\%$ ), and higher $\mathrm{MgO}$ (17.3 vs. $12.2 \mathrm{wt} \%$ ). It seems likely that some $\mathrm{Fe}$ from adjacent fine-grained regions migrated into small voids where it formed PCP. The more compact inner layers had fewer voids and allowed less PCP formation.

\subsection{Lineations in interchondrule regions}

In several CM chondrites, bright PCP assemblages appear to be oriented in curvilinear arrays suggesting shear (or flow). The region of Y791198 in Fig. 2a has an apparent $\mathrm{E}-\mathrm{W}$ lineation in the matrix outside the mantles. This is more evident in Fig. 12a of this same meteorite, where the illustrated region exhibits a strong lineation running WSW-ENE across the region. The lineation consists of discontinuous $450-\mu \mathrm{m}$-long PCP-rich bands in the matrix extending past DFM mantles. The PCP trail in Fig. 12a appears to be roughly parallel to the dark mantle at the lower border of the high- $\mathrm{FeO}$ olivine chondrule in the center of the image. The same type of lineation is visible in Fig. $2 b$ where it runs $\mathrm{N}-\mathrm{S}$. (Note that Fig. $2 \mathrm{~b}$ is rotated $90^{\circ}$ relative to Fig. 2a, so the lineation is actually oriented in the same direction.)

PCP-rich materials in a region of QUE 97990 (center of Fig. 12b) are oriented approximately E-W within $600-\mu \mathrm{m}-$ long trails. The trails appear to bend ("flow") around the low- $\mathrm{FeO}$ porphyritic chondrules at the left of the image.

\section{Discussion}

\subsection{Structures formed by fine-grained materials in the solar nebula}

Going back at least to Huss et al. (1981), it has been a widely held cosmochemical assumption that the finegrained chondrule "rims" on ordinary and carbonaceous 

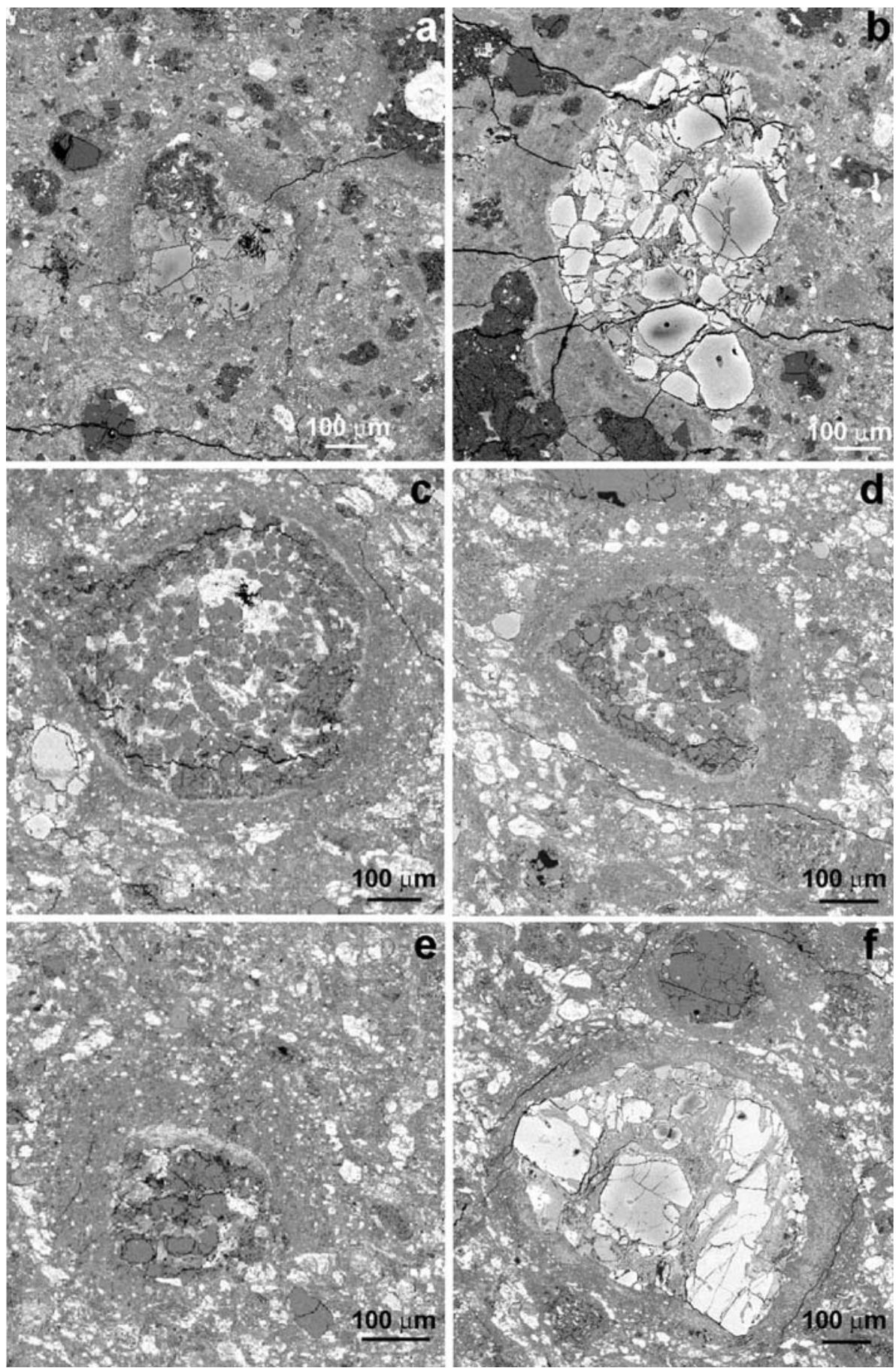

Fig. 10. Chondrules with dark mantles in Murchison and QUE 99355. (a) High-FeO porphyritic olivine chondrule fragment in Murchison with a dark mantle that grades into matrix material at bottom right. (b) High-FeO porphyritic olivine chondrule in Murchison with a dark mantle that has a thin, discontinuous inner BSE-bright rim around the chondrule. (c) Low-FeO porphyritic olivine chondrule in QUE 99355 with a thin inner BSE-bright rim that wraps around $\sim 75 \%$ of the chondrule. (d) Low-FeO porphyritic olivine chondrule in QUE 99355 with a thin, discontinuous BSE-bright inner rim in its dark mantle. (e) Small low-FeO porphyritic chondrule fragment in QUE 99355 with a discontinuous layer of BSE-bright material in its ill-defined dark mantle. (f) High-FeO porphyritic olivine chondrule in QUE 99355 with a dark mantle containing BSE-bright and dark layers. All images in BSE.

chondrites obtained their observed textures as a result of agglomeration processes occurring in the solar nebula.

The problem with this belief is that there are no smallscale nebular processes that lead to significant compaction of micrometer-size materials. When these materials collide with each other or with millimeter-size chondrules, they either stick to the first surface they touch or they do not adhere. This conclusion has been reached both by modeling (e.g., Dominik and Tielens, 1997) and in laboratory simulations (e.g., Blum and Schräpler, 2004). 


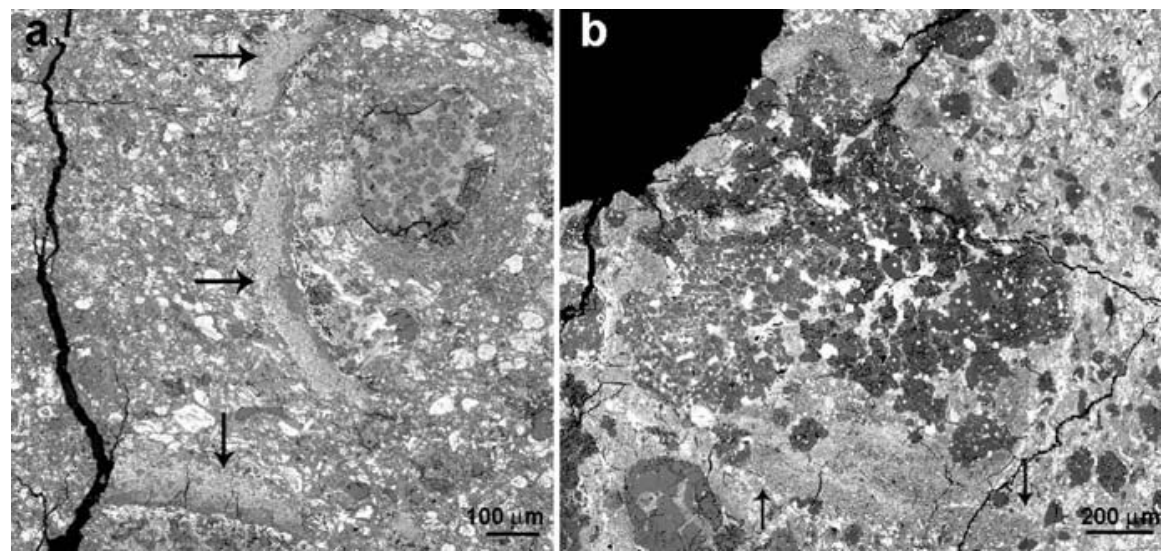

Fig. 11. Detached clasts of dark mantle material. (a) Three pieces of a layered dark mantle in QUE 99355 (arrows). The pieces are oriented in different directions but are of similar size and thickness; they probably once formed parts of a continuous mantle around a coarse-grained object. (b) Elongated detached fragment of a dark mantle in QUE 97990 (bottom, arrows). The fragment does not appear to be part of the dark mantle that surrounded the large low-FeO porphyritic olivine chondrule in the image. Both images are in BSE.

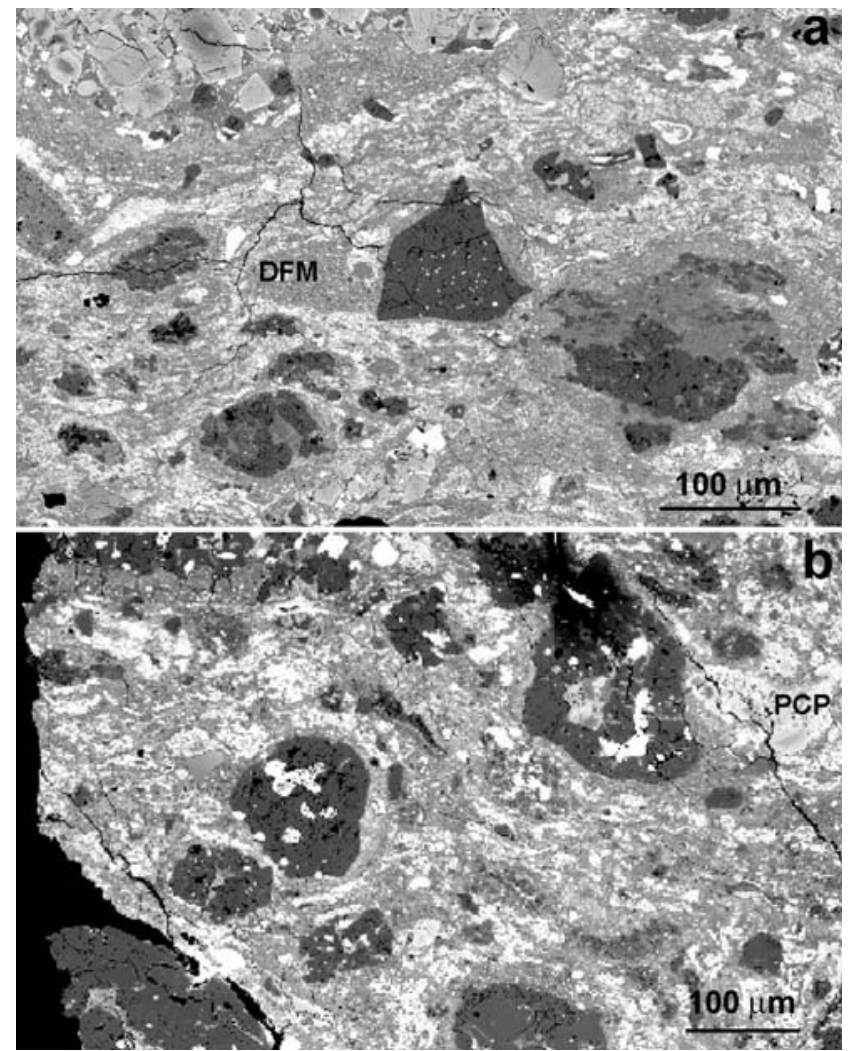

Fig. 12. Lineation features. (a) Angular low-FeO olivine grain (center) in Y791198 embedded in a highly irregular DFM clump that is connected to another clump surrounding a chondrule fragment. PCP material forms a strong lineation running WSW-ENE across the region. (b) PCP-rich region in QUE 97990 exhibiting a strong lineation running E-W across the region. BSE images.

Agglomeration efficiency and compaction are enhanced if particles collide with clusters because the latter can respond inelastically (Dominik and Tielens, 1997). Sticking and compression are also enhanced if clusters collide with clusters. However, modeling shows that such collisional compression still leaves $>50 \%$ porosity, far greater than that observed in CM DFM including mantles.

These simulations assume that the adhesion is the result of (the very weak) van der Waals forces. Numerous authors have suggested "glue" of other sorts including carbonaceous oils and water frost. However, if these "glues" were present, it seems probable that they would cause assemblages to become even more porous as pointy protuberances stuck together.

In the nebula there is a competition between growth and fragmentation. At higher interparticle velocities there will be more compaction than at lower velocities, but also more fragmentation. Depending on the nature of the grains (especially their compositions, shapes, and size distributions), there will be some maximum velocity at which assemblage destruction exactly equals assemblage growth. If turbulent velocities exceed this critical value, large assemblages cannot form. In a two-dimensional simulation involving spherical, $100-\mu \mathrm{m}$ particles, Dominik and Tielens (1997) were able to get cluster growth at velocities up to $10 \mathrm{~m} \mathrm{~s}^{-1}$ but other simulations suggest lower maximum velocities (Blum, 2004).

Thus, although cluster collisions cause some compaction, porosities as low as those in meteorites are never achieved. Dominik and Tielens (1997) did not give an estimate of the minimum porosity that can be achieved for silicates in the nebula. The lowest porosity they quote is $53 \%$ for ice grains in the interstellar medium. They state that this is the minimum porosity that can be achieved in a two-dimensional simulation.

Blum (2004) addressed the issue of mechanical composition of dust aggregates. Static compression experiments at pressures of $\sim 4 \times 10^{5} \mathrm{~Pa}$ (corresponding to impact velocities of $50 \mathrm{~m} \mathrm{~s}^{-1}$ ) only reduced the porosities of monodisperse diamond grains to $66 \%$. He also noted that gravitational compression in asteroids having radii $>100 \mathrm{~km}$ produces the same static pressures. Thus, the first generation of asteroids would likely have retained high, $>50 \%$, porosities. 


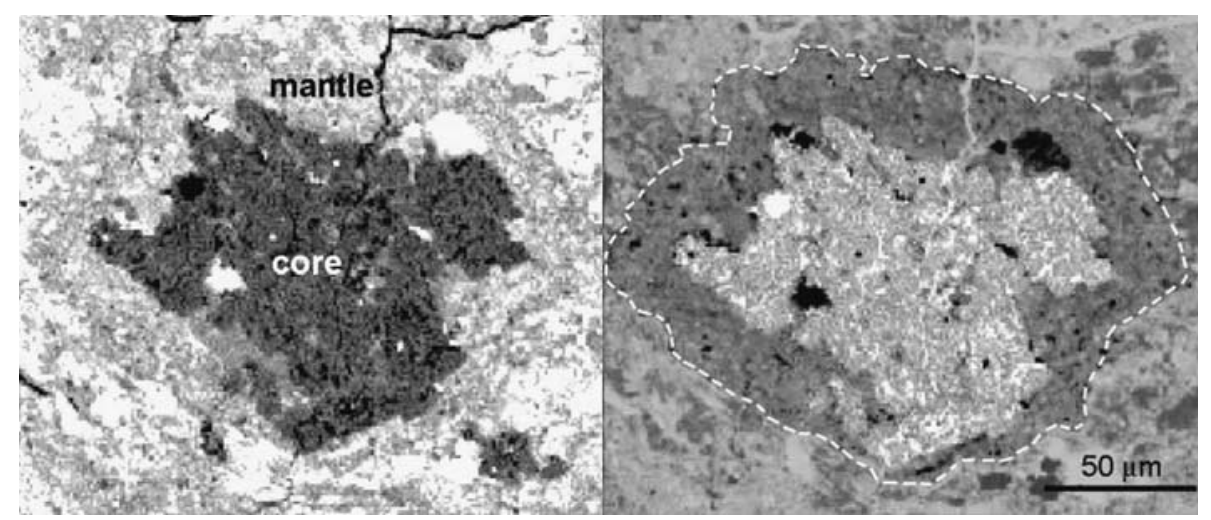

Fig. 13. An example of core-mantle integration used in estimating mantle thicknesses. Shown on the left the original BSE image. The outlined area on the right defines the total area of mantle and core; modal integration of the inner, brighter region defines the area of the core. See text for additional details.
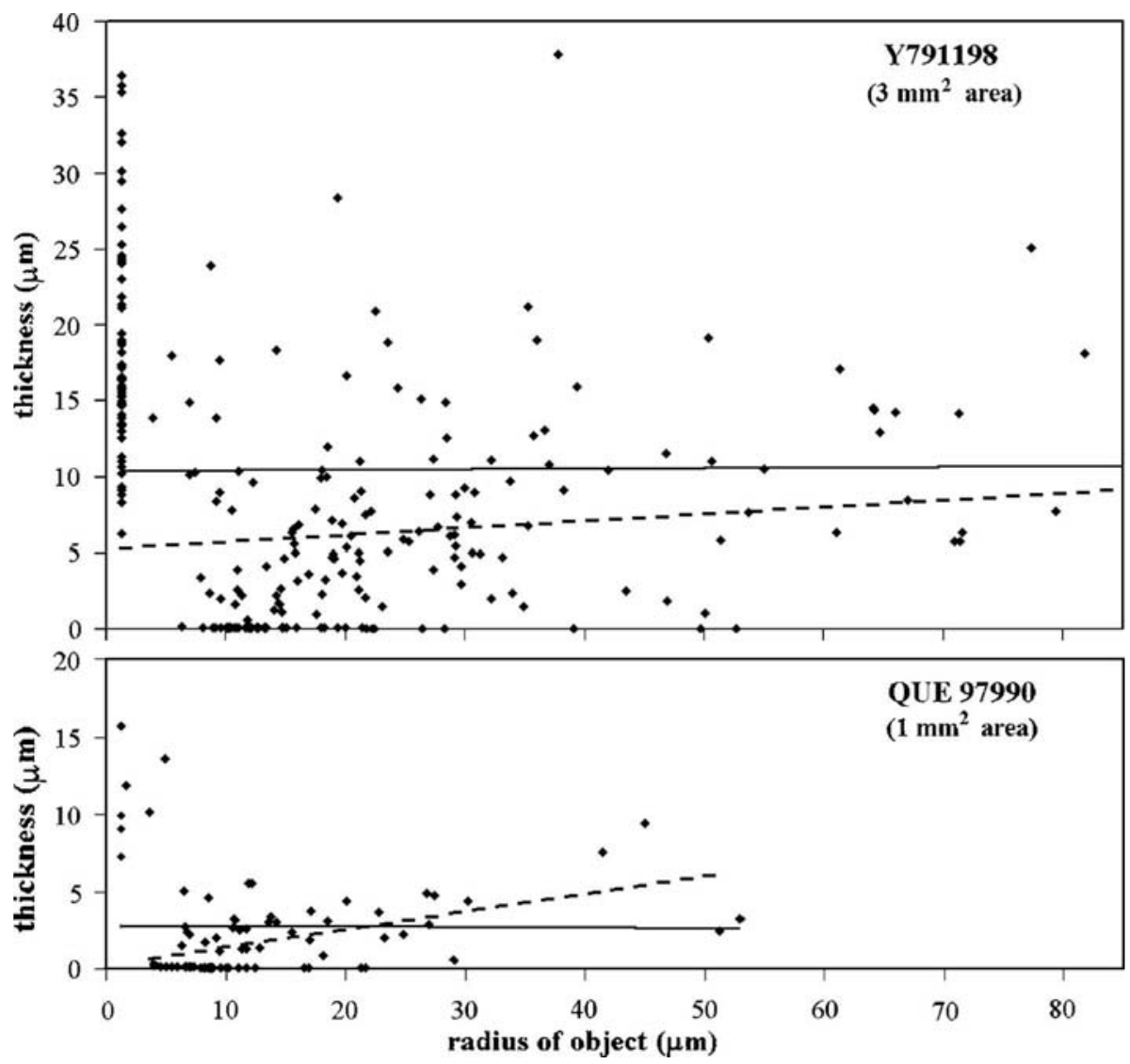

Fig. 14. Plots of Y791198 and QUE 97990 showing the relationship between mantle thickness and the radius of enclosed objects. The chondrules and other inclusions contained in QUE 97990 are significantly smaller than in Y791198.

Table 1

Objects surveyed in the study of the correlation between mantle thickness and diameter

\begin{tabular}{llllllll}
\hline Meteorite & Surveyed area $\left(\mathrm{mm}^{2}\right)$ & \#objects & DFM lumps & Mantled chondrules & Unmantled chondrules & Other objects* & \% mantled chondrules \\
\hline Y791198 & 3 & 261 & 79 & 116 & 37 & 27 & 75.8 \\
Y791198 & Entire thin section & 78 & 14 & 50 & 6 & 8 & 89.2 \\
QUE97990 & 1 & 81 & 9 & 42 & 24 & 6 & 63.6 \\
\hline
\end{tabular}

The column labeled "other objects" includes CAIs, metal grains, bright nodules, or unidentified objects. The criterion to categorize a chondrule as unmantled is that the surrounding DFM "coat" would be less than $1.5 \mu \mathrm{m}$ thick. 


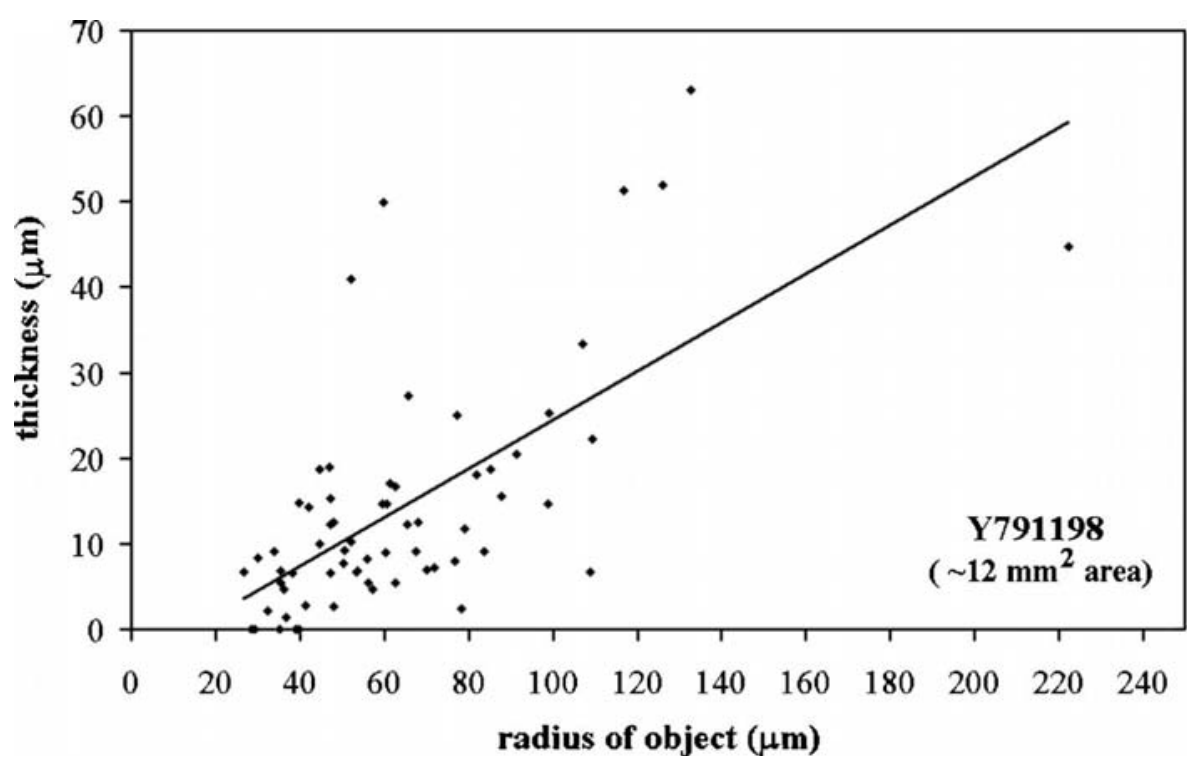

Fig. 15. Correlation between mantle thickness and radius of the enclosed object for the Y791198,90-1 thin section. Sixty-six objects larger than $35 \mu$ m are shown. The trend line is the least-squares line through all of the data. The largest objects exhibit a significant dispersion and do not lie near the trend line. The correlation would disappear if the small materials (upper part of Fig. 14) were included.

Table 2

Bulk compositions $(\mathrm{wt} \%$ ) of inner layers and speckled layers within mantles around CM chondrules

\begin{tabular}{|c|c|c|c|c|}
\hline \multirow{2}{*}{$\begin{array}{l}\text { Meteorite } \\
\text { layer }\end{array}$} & \multicolumn{2}{|l|}{ Y791198 } & \multicolumn{2}{|l|}{ QUE 97990} \\
\hline & Inner layer & Speckled layer & Inner layer & Speckled layer \\
\hline Points & 26 & 31 & 36 & 39 \\
\hline $\mathrm{SiO}_{2}$ & 23.9 & 29.8 & 20.8 & 24.8 \\
\hline $\mathrm{TiO}_{2}$ & 0.08 & 0.07 & 0.04 & 0.06 \\
\hline $\mathrm{Al}_{2} \mathrm{O}_{3}$ & 2.9 & 1.9 & 3.2 & 2.2 \\
\hline $\mathrm{FeO}$ & 32.3 & 25.8 & 34.4 & 34.8 \\
\hline $\mathrm{Cr}_{2} \mathrm{O}_{3}$ & 0.39 & 0.43 & 0.27 & 0.34 \\
\hline $\mathrm{MnO}$ & 0.22 & 0.25 & 0.18 & 0.20 \\
\hline $\mathrm{MgO}$ & 12.2 & 17.3 & 12.1 & 13.2 \\
\hline $\mathrm{CaO}$ & 0.34 & 0.25 & 0.90 & 0.81 \\
\hline $\mathrm{Na}_{2} \mathrm{O}$ & 0.43 & 0.32 & 0.61 & 0.67 \\
\hline $\mathrm{K}_{2} \mathrm{O}$ & 0.23 & 0.20 & 0.10 & 0.10 \\
\hline $\mathrm{P}_{2} \mathrm{O}_{5}$ & 0.20 & 0.11 & 0.43 & 0.35 \\
\hline $\mathrm{NiO}$ & 2.1 & 2.3 & 2.5 & 2.4 \\
\hline $\mathrm{S}$ & 3.8 & 2.6 & 3.8 & 3.0 \\
\hline Total & 79.1 & 81.3 & 79.3 & 82.9 \\
\hline $\mathrm{SiO}_{2} / \mathrm{MgO}$ & 2.0 & 1.7 & 1.7 & 1.9 \\
\hline $\mathrm{FeO} / \mathrm{MgO}$ & 2.6 & 1.5 & 2.8 & 2.6 \\
\hline $\mathrm{FeO} / \mathrm{SiO}_{2}$ & 1.4 & 0.87 & 1.7 & 1.4 \\
\hline
\end{tabular}

These studies indicate that the observed low porosities in mantles around chondrules and inclusions in CM chondrites are produced by collisions in asteroidal settings. During the growth from kilometer-size to $100-\mathrm{km}$-size asteroids, orbits became less circular and impact velocities gradually increased. In the asteroid belt today, the mean velocity is $5 \mathrm{~km} \mathrm{~s}^{-1}$. Porous asteroids colliding at velocities of $1 \mathrm{~km} \mathrm{~s}^{-1}$ or higher would have experienced appreciable compaction (and, at the higher end of the velocity spectrum, large amounts of impact heating). We note that collapse of pore space in an impact is an irreversible thermodynamic process (Melosh, 1989). In some cases these asteroids would have lost ejecta at velocities that exceeded the escape velocity, but the material that formed recoverable meteorites is the fraction that experienced appreciable compaction while remaining on the asteroid.

\subsection{Temporal relationship between compaction and aqueous alteration}

There is widespread agreement that PCP formed during secondary alteration under aqueous conditions. In $\mathrm{CM}$ chondrites most of the PCP is present as coarse $(\geqslant 20 \mu \mathrm{m})$ assemblages in the interchondrule regions. As was first suggested to us by M. Zolensky (pers. comm., ca. 2000), the reason that most PCP grew to coarse sizes seems to be because it could grow rapidly within voids. Enhanced growth rates in voids could reflect: (a) greater access to the aqueous fluid that was both a leach solution for unstable phases and a transport medium and (b) the ability of individual phases to grow in these sites without impingement. If the voids were small, as for example, inside chondrule mantles, the resulting PCP clumps were small; where voids in the meteorite matrix were larger (e.g., in Cold Bokkeveld), PCP clumps tens of micrometers in size could form.

If we accept this working model, it implies that compaction to form the fine dark materials occurred before aqueous alteration. If the reverse were true, PCP would have filled the interstices between the fine grains, resulting in large additions of PCP to these fine materials, making them much brighter and/or speckled in BSE images.

\subsection{Origin of dark mantles}

We considered three models for the origin of dark mantles. (1) The traditional view is that mantles are fine-grained 
rims acquired in the solar nebula by dust grains sticking to orbiting, "free-floating" chondrules, inclusions, and mineral fragments (Huss et al., 1981; Metzler et al., 1992). We reject this model because there appear to be no mechanical processes that can produce compaction in the solar nebula, and because the detailed evidence (e.g., more compaction next to chondrule-size incompressible objects) is inconsistent with the properties expected to be produced by low-velocity impacts in the nebula. The presence of mantles around PCP clumps and calcite grains (Figs. 3 and 4 of Metzler et al., 1992), which almost certainly formed on the parent body during alteration, refutes a nebular origin for the mantles. (2) Dark mantles were acquired in a wet regolith on the parent body, possibly by chondrules and inclusions "sloshing about in the mud" (Sears et al., 1993; based on a suggestion of H.Y. McSween). Sears et al. also suggested that the thick mantles around some chondrules may have formed by aqueous alteration of primary metal- and sulfide-rich rims. We reject this model because it fails to account for the low PCP abundance in dark fine materials and because aqueous alteration cannot readily account for the high degree of compaction relative to nebular porosities. (3) Mantles are the result of asteroidal compaction of porous DFM around chondrules and inclusions. The degree of compaction was somewhat higher near incompressible objects such as chondrules. This compaction occurred prior to most aqueous alteration. These multiple compaction events were followed by shear-produced abrasion and rounding. Some of these shear deformations occurred after aqueous alteration. This is the model we favor.

This model is supported by the observations of Chizmadia et al. (2005) who determined that fine-grained rims around chondrules and refractory inclusions in the CO3.0 chondrite ALHA77307 are compositionally similar even though the objects they surround presumably formed at different times in different nebular regions. This is consistent with the rims having formed from fine-grained porous matrix materials that were compacted around chondrules and inclusions during impact events on the parent body.

Vogel et al. (2003) investigated ca. 200- $\mu \mathrm{m}$-size regions that they identified as matrix and rims, but they acknowledged the possibility of cross contamination. The chondrule "rims" in CR2 Renazzo have lower concentrations of primordial ${ }^{36} \mathrm{Ar}$ and, possibly, ${ }^{20} \mathrm{Ne}$ than "matrix," but it is not clear how significant these results are for testing different models of chondrule-rim origin.

The mantles around chondrules, inclusions, and mineral grains are noticeable mainly because they are darker and finer-grained than bright regions of the surrounding materials. This contrast in brightness is due to the lower amounts of Fe-rich phases such as sulfides and PCP (cronstedtite and tochilinite) in the dark mantles, as is evident in Figs. 3a-c. As discussed above, it appears that PCP grew faster in porous regions. It therefore follows that the dark mantles are poorer in PCP because they were less porous when aqueous alteration occurred (we will later address the issue of the source of the $\mathrm{Fe}$ ). The lower porosity of the mantles also minimized the permeation of aqueous fluids and thus allowed the preservation of relatively high $\mathrm{FeO}$ contents (the Fe oxidation state is not known) in the most primitive mantles in QUE 97990, Y791198, Kivesvaara (this work; Metzler et al., 1992) and pre-solar SiC grains in some dark mantles in Murchison and Cold Bokkeveld (Swan and Walker, 1998). We therefore conclude that compaction of dark fine materials occurred before most of the PCP was produced by aqueous alteration.

We suggest that, early in the history of the CM parent body, CM chondrite material consisted mainly of (dense) chondrules and inclusions surrounded by high-porosity DFM. Impacts selectively compacted the DFM. Because the chondrules and inclusions had no porosity, the matrix regions immediately adjacent to these objects were compacted to somewhat greater degrees. The compaction experienced by the fine-grained material around the chondrules was also roughly hydrodynamic and thus isotropic. However, as we attempt to show with an oversimplified cartoon (Fig. 16), linear compression of a "fluid" that has appreciable interparticle friction will produce increased degrees of compaction (accompanied by more fracturing) near incompressible objects such as chondrules. The compression was probably the result of several compaction events with the primary waves coming from different azimuths. At this stage there were no definable mantles, only parcels of mat-

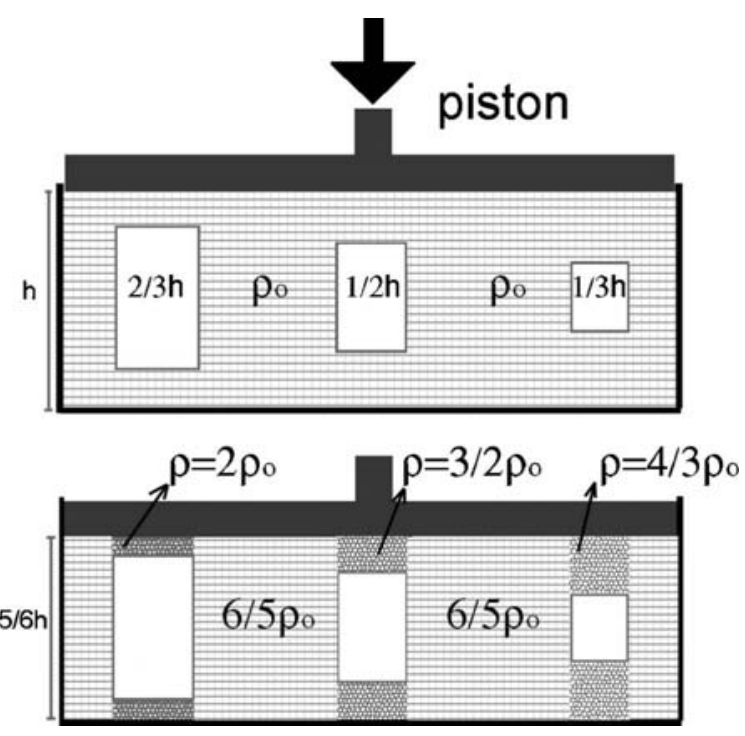

Fig. 16. Schematic diagram of a piston showing how uniaxial stress (for example, caused by a shock wave) can preferentially compress the porous matrix material near incompressible chondrules. The square shapes of the chondrules are for illustrative convenience; round chondrules would show more compression along an axis passing through the center of the chondrules. We suggest that multiple, randomly oriented, compaction events compacted fine-grained materials adjacent to chondrules and CAIs. After fragmentation of the plum-pudding-like structure, regolith gardening produced the observed mantles. In the diagram, $h$ is the original height of the solid object and $\rho_{0}$ is the original density of the interchondrule material. The arrow indicates the direction of the compressive stress. 
ter having a raisin-pudding-like structure with chondrules and refractory inclusions forming most of the raisins.

As time passed, these materials were continually gardened by impacts that created fractures and fragmentation of the dark interchondrule materials. During these events the fact that chondrules were strong and that the adjacent fine materials were somewhat more compact resulted in preferential granulation of the interchondrule DFM, and thus in the selective preservation of mantles around chondrules and inclusions. This is consistent with the fact that many DFM mantles have asymmetric or angular shapes. Isolated fine dark clasts (e.g., Figs. 8b and e, and 11a) were also produced. It seems probable that most objects experienced some rounding when chondrules and DFM clumps were rolled around in the regolith by impact tilling.

A subsequent epoch of aqueous/hydrothermal alteration produced PCP. These materials grew faster within voids. Thus, the bright parts of the interchondrule matrix appear to mark the regions that were the most porous.

Lauretta et al. (2000) noted that the chondrule mantles contained Mg-rich serpentine, known to form as a latestage alteration product of tochilinite and cronstedtite. However, this is not the only reaction that can produce $\mathrm{Mg}$ serpentine. During terrestrial metamorphism, $\mathrm{Mg}$ serpentine $\left(\mathrm{Mg}_{3} \mathrm{Si}_{2} \mathrm{O}_{5}(\mathrm{OH})_{4}\right)$ can form by hydrous alteration of forsterite $\left(\mathrm{Mg}_{2} \mathrm{SiO}_{4}\right)$ to $\mathrm{Mg}$ serpentine and brucite $\left(\mathrm{Mg}(\mathrm{OH})_{2}\right)$ Eq. (1) or by the hydration of forsterite and enstatite $\left(\mathrm{MgSiO}_{3}\right)$ Eq. (2):

$$
\begin{aligned}
& 2 \mathrm{Mg}_{2} \mathrm{SiO}_{4}+3 \mathrm{H}_{2} \mathrm{O}=\mathrm{Mg}_{3} \mathrm{Si}_{2} \mathrm{O}_{5}(\mathrm{OH})_{4}+\mathrm{Mg}(\mathrm{OH})_{2} \\
& \mathrm{Mg}_{2} \mathrm{SiO}_{4}+\mathrm{MgSiO}_{3}+2 \mathrm{H}_{2} \mathrm{O}=\mathrm{Mg}_{3} \mathrm{Si}_{2} \mathrm{O}_{5}(\mathrm{OH})_{4}
\end{aligned}
$$

Extrapolation of the experimentally determined equilibrium curves (e.g., Figs. 4-23 of Turner, 1968) for reaction 1 shows that it requires a temperature of only $\sim 380^{\circ} \mathrm{C}$ at 1 atm pressure.

Some tochilinite-bearing PCP assemblages and calcite grains are also surrounded by dark mantles (Figs. 3 and 4f of Metzler et al., 1992). Our observations indicate that these occurrences are rare. We suggest that, in these instances, the dark fine materials initially enclosed a void, and that PCP or Ca carbonate grew inside the void.

After this episode of aqueous alteration, the PCP-rich structures suffered additional impact fragmentation, shear, and comminution in a regolith environment. PCP-rich structures that survived as large fragments are "primary rock fragments" but not, as claimed by Metzler et al. (1992), "primary accretionary rock fragments".

Because many CM chondrites are rich in solar rare gas (e.g., Heymann and Mazor, 1967; Smith et al., 1978; Schultz and Kruse, 1989), and many contain tracks produced by solar-flare protons, we know that these samples spent part of their history in a surficial regolith. Nakamura et al. (1999) and Metzler (2004) showed that the primary rock fragments do not show solar-wind or solar-flare effects. These observations were cited as evidence by Metzler (2004) that the "primary accretionary rocks" such as
Y791198 and the clasts in Cold Bokkeveld (top of Fig. 7 of Metzler et al., 1992) did not form in a regolith environment. We agree that the prima facie evidence indicates that the materials did not exist as fine grains in the regolith at the time of irradiation. However, we find no reason to conclude that these compact materials formed in the nebula. Instead, the "primary accretionary rock fragments" seem more analogous to the light-colored metamorphosed clasts in OC regolith breccias (e.g., Fig. 1 of Williams et al., 1985). In such OC breccias, solar-flare-particle tracks and solar-wind-implanted rare gases are confined to the porous (comminuted) clastic host materials; they are not detectable in the large, light-colored chondritic clasts (e.g., König et al., 1961, 1962) because of the small surface/volume ratios of these clasts. The lack of solar-flare tracks and solar-wind gas in the "primary accretionary rocks" only indicates that they were not present as dispersed, micrometer-size grains at the time of regolith stirring and solarwind irradiation.

\subsection{Origin of layering}

In the least-altered CM chondrites, those chondrule mantles that show radial layering (e.g., Figs. 4a and c) have an inner mantle that is gray with a uniform texture and an outer layer that has darker silicates and numerous, bright PCP speckles. We suggest that the outer layers experienced less compaction than the inner layers, and that PCP filling of the larger voids created the speckles.

Metzler et al. (1992) showed that some mantles (e.g., the one shown in their Fig. 15) contain bright, PCP-rich layers. To explain these layers, they suggested that the layers were accreted in zones in the solar nebula where all the fine materials consisted of PCP (in addition to the more common zones where fine materials had not become PCP). We find it hard to conceive of a nebular process that would convert all the fine materials in any nebular zone to PCP. It seems much more plausible that concentric cracks formed in these mantles during impact rarefaction, and that these later became filled with PCP during aqueous alteration. Such a scenario can account for the PCP-rich intermediate layer around the chondrule in Fig. 7.

\subsection{Matrix lineations}

Petrofabrics in ordinary chondrites (Dodd, 1965; Martin and Mills, 1980) have been ascribed to impact-induced deformation of chondrite whole rocks (Sneyd et al., 1988). The petrofabrics in some CV (Cain et al., 1986) and CR (Weisberg et al., 1993) chondrites probably formed analogously.

Chondrules in some CM chondrites (e.g., EET 83334) are also flattened and oriented (M.E. Zolensky, pers. commun., 2004). This implies that the petrofabrics in CM chondrites also formed by impact-induced deformation. We suggest that this process accounts for the foliation defined by oriented phyllosilicates (Fujimura et al., 
1982) as well as the curvilinear arrays of fine dark materials and PCP-rich materials in portions of the matrices of several CM chondrites (e.g., Figs. 2 and 12). In the portions of Y791198 shown in Figs. 2 and 12a, these two materials seem to form parallel bands, but the PCP-rich material shows greater evidence of squeezing deformation. This is consistent with the compact, dark mantles being more resistant to deformation than the PCP-rich materials.

\subsection{Source of the PCP Fe}

Much of the Fe in CM chondrites that is now present as PCP is inferred to have formed during aqueous alteration on the parent asteroid. This raises the question of where the $\mathrm{Fe}$ was sited in the unaltered (i.e., nebular) materials prior to transport and precipitation as PCP and other alteration phases. It seems likely that much of this Fe was present in fine metallic $\mathrm{Fe}-\mathrm{Ni}$ and sulfide grains in the matrix; a minor fraction of the Fe originated in coarser metal and sulfide grains both within chondrules and as isolated grains in the matrix. The least-altered CM2 chondrites (e.g., QUE 97990) contain much more metallic $\mathrm{Fe}-\mathrm{Ni}$ than the morealtered $\mathrm{CM}$ chondrites. It is also possible that ferroan mafic silicate grains in the primitive matrix also served as a source of Fe.

\section{Conclusions}

CM chondrites have been affected by such parent-body processes as aqueous alteration, brecciation, and impact-induced deformation. Our observations of nine CM chondrites that span the aqueous alteration sequence show that the dark fine materials (DFM) are present as major textural features that surround chondrules and inclusions but are largely independent of these objects; there are many cases where DFM around chondrules appear to grade into surrounding matrix material. Many occurrences of DFM are isolated clasts or bands that do not surround any coarse objects.

If we limit ourselves to dark materials that surround chondrules, inclusions (or fragments of these) that exceed $20 \mu \mathrm{m}$ in mean radius, we find no correlation between mantle thickness and the size of the enclosed object. We find a moderate correlation if we consider only those fine materials that surround central objects (e.g., chondrules) having radii $>35 \mu \mathrm{m}$. However, these mantles are $<50 \%$ of the DFM in the investigated CM chondrites.

Layering of mantles appears to result from differences in porosity. Iron-rich phases grew more readily in pores or cracks as aqueous fluids moved through them and precipitated PCP.

We conclude that dark mantles around chondrules and inclusions formed on the CM parent asteroid by a sequence of events including impact-compaction of matrix material around chondrules and inclusions (creating lower porosity in zones immediately adjacent to the chondrules and inclusions). This was followed by aqueous alteration and con- comitant growth of phases in porous regions, mostly away from chondrules and inclusions.

These processes created the materials described as "primary accretionary rocks" by Metzler et al. (1992) and inferred by them to have originated in the solar nebula. In our opinion, all of the evidence is consistent with the formation of these structures by asteroidal processes. Fragmentation and comminution of these rocks in a regolith environment produced intact rock fragments admixed with comminuted materials. The small mean size of the latter materials resulted in high surface/volume ratios and thus high concentrations of solar-wind gases and solar-flare particle tracks. The low surface/volume ratios of the "primary accretionary rock" fragments precluded them from acquiring detectable tracks or solar-wind gas; they are analogous to the light-colored metamorphosed clasts in ordinarychondrite regolith breccias (which also lack solar-flare tracks and solar-wind gas).

\section{Acknowledgments}

We are most grateful to Knut Metzler for providing detailed thin-section images despite knowing of our different interpretations. We also thank Mike Zolensky for past and present discussions and rapid answers to our numerous queries. Jay Melosh and Adrian Brearley provided helpful comments. We thank Frank Kyte for key technical assistance in the preparation of the X-ray maps. We also thank Dante Lauretta and an anonymous reviewer for helpful comments on the manuscript. We are grateful to the curators at the Smithsonian Institution, NASA Johnson Space Center, and the National Institute of Polar Research (Japan) for the loan of CM chondrite thin sections. This work was supported in roughly equal degrees by NASA Grants NAG5-12967 (A.E. Rubin) and NAG5-12887 (J.T. Wasson). J.M. Trigo-Rodriguez is grateful to the UCLA Astrobiology Program and the Spanish State Secretary of Education and Universities for postdoctoral support.

Associate editor: Alexander N. Krot

\section{References}

Barber, D.J., 1981. Matrix phyllosilicates and associated minerals in C2M carbonaceous chondrites. Geochim. Cosmochim. Acta 45, 945-970.

Blum, J., 2004. Grain growth and coagulation. Astrophys. Dust, ASP Conf. Series 309, 369-391.

Blum, J., Schräpler, R., 2004. Structure and mechanical properties of highporosity macroscopic agglomerates formed by random ballistic deposition. Phys. Rev. Lett. 93, 115503-1-115503-4.

Blum, J., Wurm, G., 2000. Experiments on sticking, restructuring, and fragmentation of preplanetary dust aggregates. Icarus 143, 138-146.

Brearley, A.J., Chizmadia, L.J., 2005. On the behavior of phosphorus during the aqueous alteration of CM2 carbonaceous chondrites. Lunar Planet. Sci. 36 (CD-ROM) abstract\#2176.

Brearley, A.J., Geiger, T., 1991. Mineralogical and chemical studies bearing on the origin of accretionary rims in the Murchison CM2 carbonaceous chondrite (abstract). Meteoritics 26, 323. 
Browning, L., McSween, H., Zolensky, M., 1996. Correlated alteration effects in CM carbonaceous chondrites. Geochim. Cosmochim. Acta $\mathbf{6 0}$, 2621-2633.

Bunch, T., Chang, S., 1980. Carbonaceous chondrites-II: carbonaceous chondrite phyllosilicates and light element geochemistry as indicators of parent body processes and surface conditions. Geochim. Cosmochim. Acta 44, 1543-1577.

Cain, P., McSween, H.Y., Woodward, N.B., 1986. Structural deformation of the Leoville chondrite. Earth Planet. Sci. Lett. 77, 165-175.

Chizmadia, L.J., Rubin, A.E., Wasson, J.T., 2002. Mineralogy and petrology of amoeboid olivine inclusions in CO3 chondrites: relationship to parent-body aqueous alteration. Meteorit. Planet. Sci. 37, 1781-1796.

Chizmadia, L.J., Scott, E.R.D., Krot, A.N., 2005. Fine-grained rims around chondrules and refractory inclusions in ALHA77307 are compositionally similar (abstract). Meteorit. Planet. Sci. 40, A29.

Clayton, R.N., Mayeda, T.K., 1984. The oxygen isotope record in Murchison and other carbonaceous chondrites. Earth Planet. Sci. Lett. 67, 151-161.

Cuzzi, J.N., 2004. Blowing in the wind: III. Accretion of dust rims by chondrule-sized particles in a turbulent protoplanetary nebula. Icarus 168, $484-497$

Cuzzi, J.N., Hogan, R.C., Paque, J.M., Dobrovolskis, A.R., 1998. Chondrule rimming by sweepup of dust in the protoplanetary nebula: constraints on primary accretion. Lunar Planet. Sci. 29 (CD-ROM), abstract\#1439.

Dodd, R.T., 1965. Preferred orientation of chondrules in chondrites. Icarus 4, 308-316.

Dominik, C., Tielens, A.G.G.M., 1997. The physics of dust coagulation and the structure of dust aggregates in space. Astrophys. J. 480, 647-673

DuFresne, E.R., Anders, E., 1962. On the chemical evolution of the carbonaceous chondrites. Geochim. Cosmochim. Acta 26, 1085-1114.

Fuchs, L.H., Olsen, E., Jensen, K.J., 1973. Mineralogy, mineral-chemistry, and composition of the Murchison (C2) meteorite. Smithson. Contrib. Earth Sci. 10, 1-39.

Fujimura, A., Kato, M., Kumazawa, M., 1982. Preferred orientation of phyllosilicates in Yamato-74642 and -74662, in relation to deformation of C2 chondrites. Proc. Symp. Ant. Met. 7, 207-215.

Hanowski, N.P., Brearley, A.J., 2001. Aqueous alteration of chondrules in the CM carbonaceous chondrite, Allan Hills 81002: implications for parent body alteration. Geochim. Cosmochim. Acta 65, 495-518.

Heymann, D., Mazor, E., 1967. Light-dark structure and rare gas content of the carbonaceous chondrite Nogoya. J. Geophys. Res. 72, 2704-2707.

Hua, X., Wang, J., Buseck, P.R., 2002. Fine-grained rims in the Allan Hills 81002 and Lewis Cliff 90500 CM2 meteorites: their origin and modification. Meteorit. Planet. Sci. 37, 229-244.

Huss, G.R., Keil, K., Taylor, G.J., 1981. The matrices of unequilibrated ordinary chondrites: implications for the origin and history of chondrites. Geochim. Cosmochim. Acta 45, 33-51.

Jarosewich, E., 1990. Chemical analyses of meteorites: a compilation of stony and iron meteorite analyses. Meteoritics 25, 323-337.

Kerridge, J.F., 1972. Iron transport in chondrites: evidence from the Warrenton meteorite. Geochim. Cosmochim. Acta 36, 913-916.

Kerridge, J.F., Bunch, T.E., 1979. Aqueous alteration on asteroids: evidence from carbonaceous chondrites. In: Gehrels, T. (Ed.), Asteroids. Univ. Arizona Press, pp. 745-765.

Kojima, T., Yada, S., Tomeoka, K., 1995. Ca,Al-rich inclusions in thre Antarctic CO3 chondrites, Yamato-81020, Yamato-82050, and Yamato-790992: record of low-temperature alteration. Proc. NIPR Symp. Antarctic Meteorites 8, 79-96.

König, H., Keil, K., Hintenberger, H., Wlotzka, F., Begemann, F., 1961. Untersuchungen an Steinmeteoriten mit extrem hohem Edelgasgehalt. I. Der Chondrit Pantar. Zeitschr. Naturforsch. A 16, 1124-1130.

König, H., Keil, K., Hintenberger, H., 1962. Untersuchungen an Steinmeteoriten mit extrem hohem Edelgasgehalt. II. Der Chondrit Tabor. Zeitschr. Naturforsch. A 17, 357-358.

Krot, A.N., Scott, E.R.D., Zolensky, M.E., 1995. Mineralogical and chemical modification of components of CV3 chondrites: nebular or asteroidal processing? Meteoritics 30, 748-775.
Krot, A.N., Scott, E.R.D., Zolensky, M.E., 1997. Origin of fayalitic olivine rims and lath-shaped matrix olivine in the CV3 chondrite Allende and its dark inclusions. Meteorit. Planet. Sci. 32, 31-49.

Lauretta, D.S., Hua, X., Buseck, P.R., 2000. Mineralogy of fine-grained rims in the ALH 81002 CM chondrite. Geochim. Cosmochim. Acta 64, 3263-3273.

Martin, P.M., Mills, A.A., 1980. Preferred orientations in meteorites. Earth Planet. Sci. Lett. 51, 18-25.

McSween, H.Y., 1979. Alteration in CM carbonaceous chondrites inferred from modal and chemical variations in matrix. Geochim. Cosmochim. Acta 43, 1761-1770.

McSween, H.Y., 1987. Aqueous alteration in carbonaceous chondrites: mass balance constraints on matrix mineralogy. Geochim. Cosmochim. Acta 51, 2469-2477.

Melosh, H.J., 1989. Impact Cratering: A Geologic Process. Oxford University Press, New York, 245 pp.

Metzler, K., 2004. Formation of accretionary dust mantles in the solar nebula: evidence from preirradiated olivines in $\mathrm{CM}$ chondrites. Meteorit. Planet. Sci. 39, 1307-1319.

Metzler, K., Bischoff, A., 1996. Constraints on chondrite agglomeration from fine-grained chondrule rims. In: Hewins, R.H., Jones, R.H. Scott, E.R.D. (Eds.), Chondrules and the Protoplanetary Disk. Cambridge University Press, Cambridge, pp. 153-161.

Metzler, K., Bischoff, A., Stöffler, D., 1992. Accretionary dust mantles in CM chondrites: evidence for solar nebula processes. Geochim. Cosmochim. Acta 56, 2873-2897.

Nakamura, T., Nagao, K., Metzler, K., Takaoka, N., 1999. Heterogeneous distribution of solar and cosmogenic noble gases in $\mathrm{CM}$ chondrites and implications for the formation of CM parent bodies Geochim. Cosmochim. Acta 63, 257-273.

Paque, J., Cuzzi, J.N., 1997. Physical characteristics of chondrules and rims, and aerodynamic sorting in the solar nebula. Lunar Planet. Sci. 28, 1071-1072 (CD-ROM) abstract\#1189.

Price, P.B., Hutcheon, I.D., Brady, D., MacDougall, D., 1975. Track studies bearing on solar-system regoliths. Proc. Lunar Sci. Conf. 6 3449-3469.

Richardson, S.M., 1981. Alteration of mesostasis in chondrules and aggregates from three C2 carbonaceous chondrites. Earth Planet. Sci. Lett. 52, 67-75.

Rubin, A.E., 1998. Correlated petrologic and geochemical characteristics of CO3 chondrites. Meteorit. Planet. Sci. 33, 385-391.

Rubin, A.E., Wasson, J.T., 1986. Chondrules in the Murray CM2 meteorite and compositional differences between $\mathrm{CM}-\mathrm{CO}$ and ordinary chondrite chondrules. Geochim. Cosmochim. Acta 50, 307-315.

Rubin, A.E., Trigo-Rodríguez, J.M., Wasson, J.T., 2005. A new aqueous alteration index for CM carbonaceous chondrites (abstract). Meteor. Planet. Sci. 40, A131.

Schultz, L., Kruse, H., 1989. Helium, neon, and argon in meteorites-a data compilation. Meteoritics 24, 155-172.

Sears, D.W.G., Benoit, P.H., Jie, L., 1993. Two chondrule groups each with distinctive rims in Murchison recognized by cathodoluminescence. Meteoritics 28, 669-675.

Smith, S.P., Huneke, J.C., Wasserburg, G.J., 1978. Neon in gas-rich samples of the carbonaceous chondrites Mokoia, Murchison, and Cold Bokkeveld. Earth Planet. Sci. Lett. 39, 1-13.

Sneyd, D.S., McSween, H.Y., Sugiura, N., Strangway, D.W., Nord, G.L., 1988. Origin of petrofabrics and magnetic anisotropy in ordinary chondrites. Meteoritics 23, 139-149.

Swan, P.D., Walker, R.M., 1998. Distribution of in situ silicon carbide grains in primitive meteorites and their use in identifying nebular components (abstract). Meteorit. Planet. Sci. 33, A152.

Tomeoka, K., Buseck, P.R., 1985. Indicators of aqueous alteration in CM carbonaceous chondrites: microtextures of a layered mineral containing Fe, S, O and Ni. Geochim. Cosmochim. Acta 49, 21492163.

Tomeoka, K., Kojima, T., 1998. Arcuate band texture in a dark inclusion from the Vigarano CV3 chondrite: possible evidence for early sedimentary processes. Meteorit. Planet. Sci. 33, 519-525. 
Tomeoka, K., Tanimura, I., 2000. Phyllosilicate-rich chondrule rims in the Vigarano CV3 chondrite: evidence for parent-body processes. Geochim. Cosmochim. Acta 64, 1971-1988.

Turner, F.J., 1968. Metamorphic Petrology: Mineralogical and Field Aspects. McGraw-Hill, New York, 403 pp.

Vogel, N., Wieler, R., Bischoff, A., Baur, H., 2003. Microdistribution of primordial $\mathrm{Ne}$ and $\mathrm{Ar}$ in fine-grained rims, matrices, and dark inclusions of unequilibrated chondrites - clues on nebular processes. Meteorit. Planet. Sci. 38, 1399-1418.

Wasson, J.T., 1995. Chondrites: the compaction of fine matrix and matrixlike chondrule rims (abstract). Meteoritics 30, 594-595.

Wasson, J.T., Trigo-Rodríguez, J.M., 2004. Evaporation during chondrule formation, recondensation as fine particles, and the condensation of S and other volatile elements. Lunar Planet. Sci. 35 (CD_ROM), abstract\#2140.

Weisberg, M.K., Prinz, M., Clayton, R.N., Mayeda, T.K., 1993. The CR (Renazzo-type) carbonaceous chondrite group and its implications. Geochim. Cosmochim. Acta 57, 1567-1586.

Williams, C.V., Rubin, A.E., Keil, K., San Miguel, A., 1985. Petrology of the Cangas de Onis and Nulles regolith breccias: implications for parent body history. Meteoritics 20, 331-345.

Zega, T.J., Buseck, P.R., 2003. Fine-grained-rim mineralogy of the Cold Bokkeveld CM chondrite. Geochim. Cosmochim. Acta 67, 1711-1721.

Zolensky, M.E., McSween, H.Y., 1988. Aqueous alteration. In: Kerridge, J.F., Matthews, M.S. (Eds.), Meteorites and the Early Solar System. Univ. Arizona Press, Arizona, pp. 114-143. 